\title{
Experimental Investigation of Mechanical and Fracture Properties of Offshore Wind Monopile Weldments: SLIC Inter-Laboratory Test Results
}

\author{
Ali Mehmanparast ${ }^{1 *}$, Jessica Taylor ${ }^{1}$, Feargal Brennan ${ }^{1}$, Isaac Tavares $^{2}$ \\ ${ }^{1}$ Offshore Renewable Energy Engineering Centre, Cranfield University, \\ Cranfield, Bedfordshire MK43 0AL, UK. \\ ${ }^{2}$ Centrica Renewable Energy Limited, Windsor, UK. \\ *Corresponding author: a.mehmanparast@cranfield.ac.uk
}

\begin{abstract}
S355 structural steel is commonly used in fabrication of offshore structures including offshore wind turbine monopiles. Knowledge of mechanical and fracture properties in S355 weldments and the level of scatter in these properties are extremely important for ensuring the integrity of such structures through engineering critical assessment. An interlaboratory test programme was created to characterise the mechanical and fracture properties of S355 weldments, including the base metal, heat affected zone and the weld metal, extensively. Charpy impact tests, chemical composition analysis, hardness tests, tensile tests and fracture toughness tests have been performed on specimens extracted from each of the three material microstructures. The experimental test results from this project are presented in this paper and their importance in structural integrity assessment of offshore wind turbine monopiles has been discussed. The results have shown a decreasing trend in the Charpy impact energy and $J_{\max }$ values with an increase in yield stress from base metal to heat affected zone to weld metal. Moreover, the $J_{I C}$ fracture toughness value in the heat affected zone and weld metal, are on average around $60 \%$ above and $40 \%$ below the base metal value, respectively. In addition, the average Charpy impact energy value in the heat affected zone and weld metal are around 5\% and $30 \%$ below the base metal value, respectively. The effects of mechanical and fracture properties on the critical crack size estimates have been investigated and the results are discussed in terms of the material properties impact on structural design and integrity assessment of monopiles.
\end{abstract}

Keywords: Offshore wind, Monopile, Fracture Toughness, J IC, S355 steel, Weldments.

\section{Nomenclature}

$\begin{array}{ll}a & \text { Crack Length } \\ a_{o} & \text { Initial Crack Length } \\ a_{i} & \text { Incremental Crack Length } \\ \Delta a & \text { Change in Crack Length } \\ \Delta a_{\max } & \text { Maximum Crack Growth } \\ A_{p} & \text { Plastic Area Under Load Line Displacement Curve } \\ B & \text { Specimen Thickness }\end{array}$




\begin{tabular}{|c|c|}
\hline$B_{e}$ & Effective Thickness \\
\hline$B_{n}$ & Net Thickness Between the Side-grooves \\
\hline$C_{i}$ & Load-Line Crack Opening Elastic Compliance \\
\hline$E$ & Young's Modulus \\
\hline$E^{\prime}$ & Effective Young's Modulus \\
\hline$J$ & Elastic-Plastic Fracture Mechanics Parameter \\
\hline Jelastic & Elastic Component of $J$ \\
\hline$J_{\text {plastic }}$ & Plastic Component of $J$ \\
\hline$J_{0.2 B L}$ or $J_{I C}$ & Fracture Toughness \\
\hline$J_{\max }$ & $J$ at Maximum Load \\
\hline$K$ & Linear Elastic Fracture Mechanics Parameter \\
\hline$K_{I C}$ & Critical value of $K$ Fracture Mechanics Parameter \\
\hline M & Mismatch ratio \\
\hline$W$ & Specimen Width \\
\hline$\eta$ & Geometry Dependent Constant \\
\hline$v$ & Poisson’s Ratio \\
\hline$\sigma_{\text {ref }}$ & Reference Stress \\
\hline$\sigma_{U T S}$ or UTS & Ultimate Tensile Strength \\
\hline$\sigma_{Y}$ & Yield Stress \\
\hline$\sigma_{Y, B M}$ & Yield Stress of the Base Metal \\
\hline$\sigma_{Y, W M}$ & Yield Stress of the Weld Metal \\
\hline BM & Base Metal \\
\hline $\mathrm{C}(\mathrm{T})$ & Compact Tension Specimen Geometry \\
\hline DIC & Digital Image Correlation \\
\hline ECA & Engineering Critical Assessment \\
\hline HAZ & Heat Affected Zone \\
\hline JIP & Joint Industry Project \\
\hline LLD & Load-Line Displacement \\
\hline LVDT & Linear Variable Differential Transformer \\
\hline NDT & Non-Destructive Testing \\
\hline OES & Optical Emission Spectroscopy \\
\hline PWHT & Post-Weld Heat Treatment \\
\hline $\mathrm{SD}$ & Standard Deviation \\
\hline $\mathrm{SEN}(\mathrm{B})$ & Single Edge Notched Bend Specimen Geometry \\
\hline SLIC & Structural Lifecycle Industry Collaboration \\
\hline $\mathrm{TC}$ & Test Centre \\
\hline WM & Weld Metal \\
\hline
\end{tabular}

\section{Introduction}

With growing interest in development of new offshore renewable wind farms in the UK and Europe, it is essential to reduce the levelised cost of offshore wind energy. An engineering approach for achieving this goal is to improve the structural integrity assessment procedures available for offshore wind turbines. Some of the key issues in the life assessment of these offshore assets are the need to optimise the inspection plans, reducing the maintenance costs and improving the life prediction/extension of the offshore wind monopile foundations. These sub-sea structures are fabricated by welding relatively thick structural steel plates in longitudinal and circumferential directions to form large tubular structures. During operational life these structures are subjected to 
extreme conditions in harsh offshore environments with the constant exertion of wave and wind forces causing both fatigue and corrosion damage. As a result of cyclic loads applied on monopiles, fatigue cracks often initiate at the outer surface of circumferential welds and propagate towards the inner surface, along the through-thickness direction. In order to design a monopile for a certain operational life, and also to have a reliable estimate of the remaining life in cracked monopiles, which can be obtained by estimating the time (i.e. number of cycles) required to reach a critical fatigue crack size beyond which global failure will occur, it is essential to feed accurate mechanical and fracture properties into engineering analyses. Compared to other offshore industries such as Oil $\&$ Gas, offshore wind monopiles are fabricated in much larger diameters (up to $10 \mathrm{~m}$ ) and thicknesses (up to $150 \mathrm{~mm}$ ) using contemporary materials, fabrication technologies and design techniques which are different to those in the Oil \& Gas industry [1]. Therefore, it is essential to accurately examine the structural integrity of these large-scale structures, and characterise the mechanical response, fracture properties and fatigue crack growth behaviour of the thick-walled monopile weldments in air and seawater. In order to achieve this goal, comprehensive laboratory testing needs to be performed on the base metal (BM) (also known as parent material), weld metal (WM) and the heat affected zone (HAZ) regions of the representative materials used in offshore monopile welded structures. This would support informed decisions concerning existing offshore wind structures and future developments in terms of design savings, construction and operation.

The material that is widely used in fabrication of offshore wind monopiles is S355 structural steel. Structural steels are classified based on their yield strength, $\sigma_{Y}$, and can have a wide range of properties, however they have typical similarities standardised through BS-10025 [2]. Structural steels have a high strength-weight ratio and can be formed into a range of shapes (e.g. plates, beams, angles, channels) to suit the design and manufacturing requirements. Structural steels are particularly common due to their relatively low cost, compared to alloyed and stainless steels, and versatility. Based on the data in the literature available for S355 structural steel BM, the elastic Young's modulus, $E$, for this material is around $190-220 \mathrm{GPa}[3,4]$ with the yield strength ranging from 355 to $650 \mathrm{MPa}$ and the ultimate tensile strength (UTS or $\sigma_{U T S}$ ) ranging from 490 to $700 \mathrm{MPa}$ [3-6]. Sample chemical compositions for S355 steel can frequently be found in the literature [3-7] and it can be seen that BM hardness varies from 150 to $240 \mathrm{Hv}[4,8]$. The existing experimental results show that a significant variation can be observed in fracture toughness of various structural steels. For example, the $J_{I C}$ fracture toughness value for Q345 structural steel BM has been reported as 0.48 MPam by Wang, Y. et al [9]. According to the data in the literature, the fracture toughness for S355 structural steel BM ranges from 0.1 to $0.8 \mathrm{MPam}$, depending on material preparation [10-16]. It must be noted that the fracture properties of welded joints depend on the type of welding, the filler metal, mismatch ratio and the type of welded joint $[2,15,17]$.

Experimental investigations have been carried out in recent years to characterise fatigue and corrosion-fatigue crack growth behaviour of different grades of S355 structural steels, which are widely used in offshore wind industry [18-21]. Although some limited experimental data are available on S355 structural steels within a wide range of allowable chemical compositions, there has been no independent testing research programme to experimentally investigate the level of scatter in the mechanical and fracture properties of S355 material in offshore wind monopile weldments. To obtain an improved understanding of fatigue and fracture behaviour in butt welded steel plates used in 
fabrication of offshore wind monopiles, the SLIC (Structural Lifecycle Industry Collaboration) Joint Industry Project (JIP) was created. SLIC is a joint industry venture of ten of the largest offshore wind operators (including Centrica, Dong Energy, EDF, EnBW, E.On, RWE, SSE, Statkraft, Statoil, Vattenfall) and The Crown Estate with the sponsorship of the UK's Department of Energy and Climate Change. The main aim of the SLIC project is to improve the structural design and integrity of offshore monopiles and update the corresponding international standards accordingly. As a part of this interlaboratory (i.e. round robin) test programme, the mechanical and fracture properties of offshore monopile weldments have been characterised by performing a series of blind tests, at three independent Test Centres (TC), following relevant standard test methods. It's worth noting that according to the experimental data in the literature, the mechanical and fracture properties of the material are sensitive to the temperature and specimen size [22-26]. However, the focus of this work is to examine the variability in the mechanical and fracture properties of offshore monopile weldments and investigate their subsequent effects on structural integrity assessments, rather than exploring the size and temperature effects. This is the first step for the offshore wind industry to obtain a comprehensive understanding of the material's performance in monopile weldments and more detailed studies to consider other factors influencing the structural response, including temperature, size and welding residual stresses, can be explored following on the present study. The material characterisation tests, which have been conducted in the course of this project, are; (i) Charpy impact tests, (ii) chemical composition analysis, (iii) hardness tests (both micro and macro Hv), (iv) tensile tests and (v) $J_{I C}$ fracture toughness tests. The experimental procedures for performing these tests on S355 weldments are described in this paper and the results are presented and discussed in terms of the importance of the obtained experimental data scatter in structural integrity assessment of monopile welded structures. A case study has also been presented in the discussion section to demonstrate how the observed scatter in the experimental data influences the critical crack size values calculated using the failure assessment diagrams (FAD).

\section{Specimen Design and Orientation}

The material used in the mechanical and fracture properties characterisation work package in the SLIC project is in the form of $50 \mathrm{~mm}$ and $90 \mathrm{~mm}$ thick EN-10025 S355ML grade steel plates. 4 double $\mathrm{V}$-groove multi pass butt-welded plates were supplied by 2 different manufacturers (i.e. fabricators) (denoted manufacturer A and B) and tested by 3 independent Test Centres (denoted TC1, TC2 and TC3), as summarised in Table 1. Four plates were used in total for the SLIC material characterisation work package, three of which (one $50 \mathrm{~mm}$ thick plate and two $90 \mathrm{~mm}$ thick plates) were supplied by manufacturer $\mathrm{A}$ and one plate (with $50 \mathrm{~mm}$ thickness) by manufacturer B. These plates are denoted A1, $\mathrm{A} 2, \mathrm{~A} 3$ and $\mathrm{B} 1$ in this paper. The plates were firstly rolled and then welded along the rolling direction. This was done in accordance with the tolerances specified in the standards and following the common practice in offshore wind industry. A schematic illustration of the rolling direction with respect to the weld region is shown in Figure 1. In this figure, $\mathrm{T}, \mathrm{N}$ and $\mathrm{L}$ axes are the Transverse, Normal and Longitudinal directions, respectively, with respect to the weld region. More information about the weld size and dimension of the HAZ region can be found in [19]. The minimum pre-heat temperature and maximum inter-pass temperature were $50{ }^{\circ} \mathrm{C}$ and $225{ }^{\circ} \mathrm{C}$, respectively. Gasburners were used for pre-heating the plates and the temperatures were measured by thermo crayons. The filler metal was F7A8-EH12K AWS class and Esab OK12.32/SAF Oerlikon 
OP121TT trade. Submerged arc welding (SAW) tandem-twin process was chosen to increase deposition rates and productivity. The welded plates were not post-weld heattreated (PWHT) to replicate the real life conditions in monopiles. As seen in Table 1, the first Test Centre (denoted TC1) characterised two plates (one from each manufacturer; A1 and B1) whereas the other Test Centres (TC2 and TC3) analysed one plate each. An example of the double $\mathrm{V}$-groove weld configuration for a $50 \mathrm{~mm}$ thick welded plate is given in Figure 2.

The welded plates were ground, polished and etched using 5\% Nital solution to reveal the material microstructure in the weld region prior to specimen extraction. In order to fully characterise the weld sections by considering the material inhomogeneity induced due to the large plate thickness and welding process, each of the material verification tests were carried out on the BM, HAZ and WM material microstructures. A schematic illustration of the specimen sectioning plan for A3 plate is shown in Figure 3, as an example. Fracture toughness and Charpy specimens were extracted in the T-N orientation with the crack opening direction parallel to the $\mathrm{T}$ axis and crack propagation direction along the $\mathrm{N}$ axis. All specimens were extracted at or near the mid-thickness of the welded plates. The crack plane in fracture toughness and Charpy specimens was designed in this orientation to characterise fracture properties in through-thickness direction for monopile welded sections. This orientation was chosen simply to replicate the crack growth direction in offshore wind turbine monopiles. As mentioned earlier the cracks in monopiles initiate at the outer surface near the weld toes and propagate towards the inner surface, in throughthickness direction. Tensile specimens were extracted with the gauge length oriented along the $\mathrm{T}$ axis, such that the applied load direction in tensile specimens is consistent with that of applied in fracture toughness and Charpy impact tests.

Table 1 - A summary of S355ML steel plates tested in the SLIC project

\begin{tabular}{cccc}
\hline Plate ID & Manufacturer ID & Thickness & Test Centre ID \\
\hline A1 & A & $50 \mathrm{~mm}$ & TC1 \\
\hline A2 & A & $90 \mathrm{~mm}$ & TC2 \\
\hline A3 & A & $90 \mathrm{~mm}$ & TC3 \\
\hline B1 & B & $50 \mathrm{~mm}$ & TC1 \\
\hline
\end{tabular}

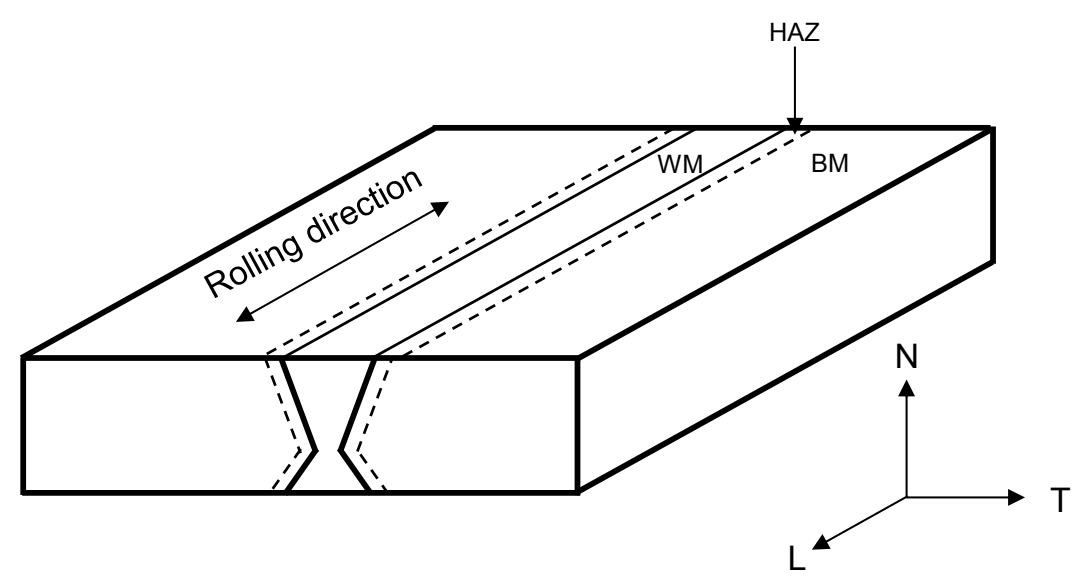

Figure 1 - A schematic illustration of the rolling direction with respect to the weld region 


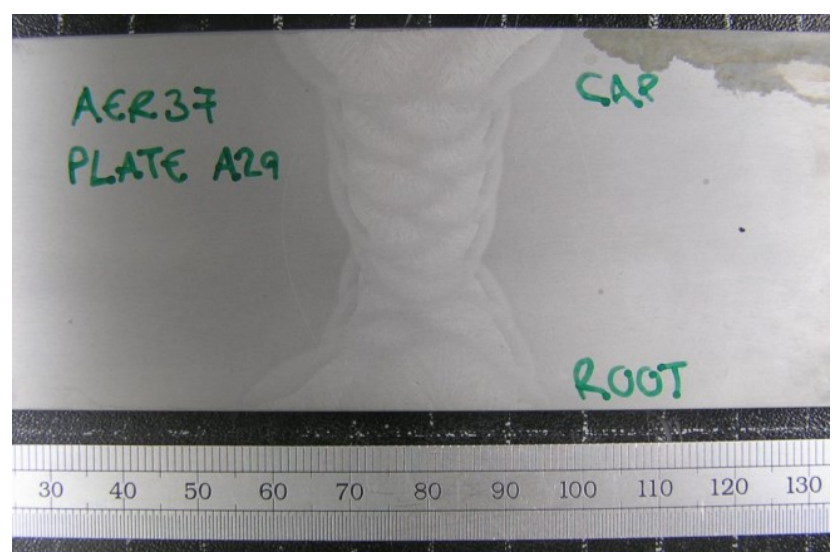

Figure 2 - An example of the side view of the weld profile in a $50 \mathrm{~mm}$ thick welded plate

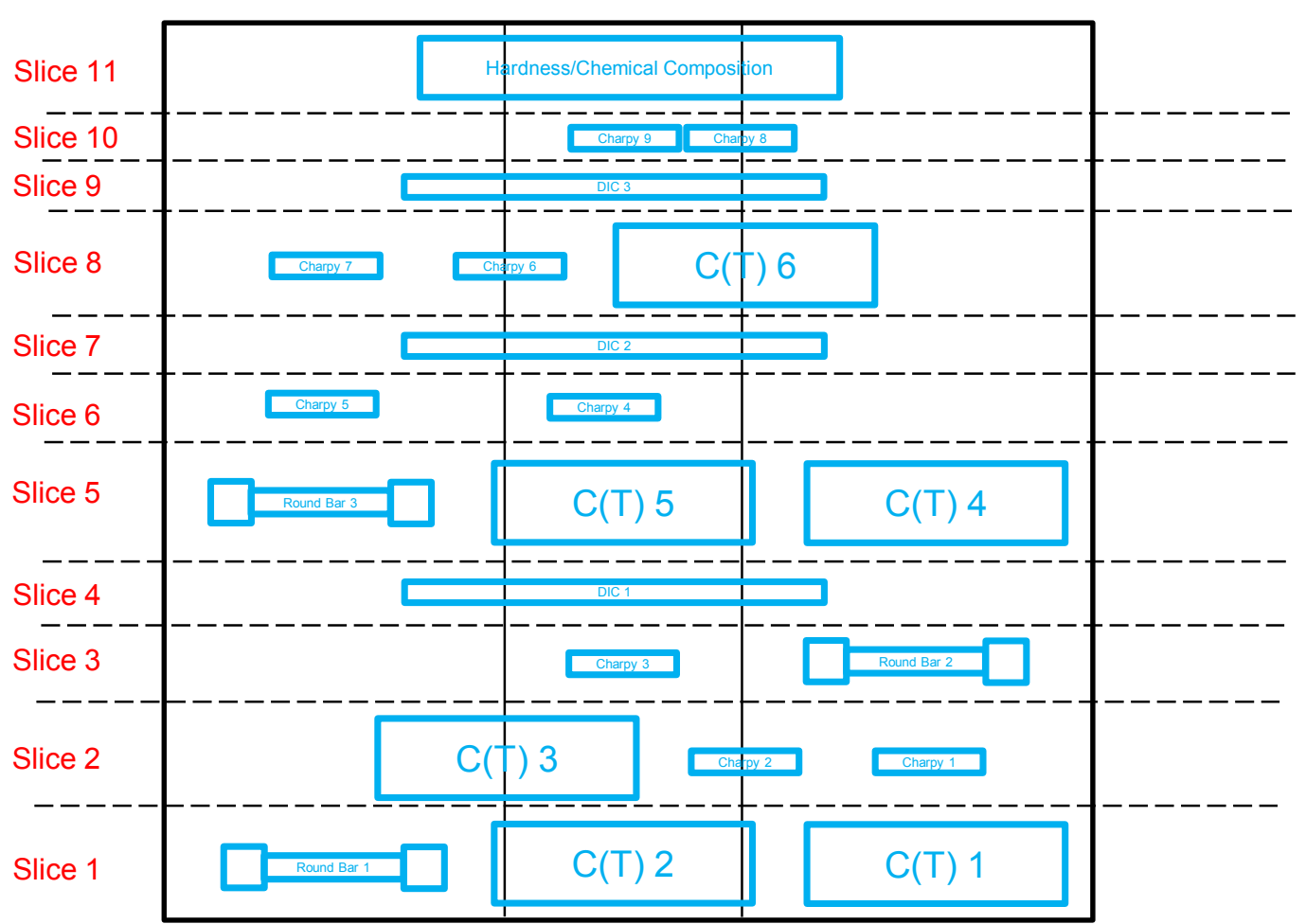

Figure 3 - Specimen sectioning plan (top view) for A3 plate

\section{$3 \quad J_{I C}$ Fracture Toughness Relations}

For ductile materials, the fracture toughness can be characterised using the elastic-plastic fracture mechanics parameter $J$. According to the ASTM Standard Test Method for Measurement of Fracture Toughness [27], the $J$ parameter can be split into an elastic element $J_{\text {elastic }}$ and a plastic element $J_{\text {plastic }}$ where: 


$$
\begin{array}{cc}
J_{\text {elastic }}=\frac{K^{2}}{E^{\prime}} & \text { Equation 1 } \\
J_{\text {plastic }}=\frac{A_{p}}{B_{n}\left(W-a_{0}\right)} \eta & \text { Equation 2 }
\end{array}
$$

where $K$ is the stress intensity factor, the solutions of which are available in the literature for a wide range of fracture mechanics specimen geometries [28], $E^{\prime}$ is the effective Young's modulus $\left(E^{\prime}=E\right.$ for plane stress conditions and $E^{\prime}=E /\left(1-v^{2}\right)$ for plane strain conditions with $v$ being the Poisson's ratio), $a_{0}$ is the initial crack length, $W$ is the specimen width, $B_{n}$ is the net thickness between the side grooves, $\eta$ is a geometry dependent function and $A_{p}$ is the plastic area under the load $v s$ displacement curve as described in ASTM E1820 [27] and BS7448-4 [29]. In Equation 2, $\eta=2$ for Single Edge Notched Bend, SEN(B), specimens and $\eta=2+0.522\left(1-a_{0} / W\right)$ for compact tension, C(T), specimens $[27,29]$.

In order to find the $J_{I C}$ fracture toughness of the material, the $J v s \Delta a$ curve (also known as $J$-resistance or $J R$ curve) needs to be generated as described in BS7448-4, where $J$ is the elastic-plastic fracture mechanics parameter and $\Delta a$ is the incremental crack growth. A blunting line needs to be constructed in the $J R$ curve using Equation 3, the slope of which is used for exclusion lines at $\Delta a$ offset of $0.1 \mathrm{~mm}$ and $\Delta a_{\max }$, which is the maximum allowable crack size in fracture toughness analysis calculated using the specimen width $W$ and the initial crack length $a_{0}$ (see Equation 4).

$$
\begin{array}{cl}
3.75 \sigma_{U T S} \Delta a=J & \text { Equation 3 } \\
\Delta a_{\text {max }}=0.1\left(W-a_{0}\right) & \text { Equation 4 }
\end{array}
$$

Fracture toughness tests can be performed using a multiple-specimen approach, where nominally identical specimens are subjected to different load levels and then the samples are broken open to measure the crack extension on the fracture surface, or using a single specimen approach where a test specimen is subjected to sequences of loading and unloading. In the latter approach, the instantaneous crack length at each peak load, $a_{i}$, can be estimated using:

$$
\begin{array}{ll}
\frac{a_{i}}{W}=1.000196-4.06319 u+11.242 u^{2} & \\
-106.043 u^{3}+464.335 u^{4}-650.677 u^{5} & \text { Equation 5 }
\end{array}
$$

where:

$$
u=\frac{1}{\left[B_{e} E C_{i}\right]^{\frac{1}{2}}+1}
$$

Equation 6

Note that Equation 5 is only valid for $\mathrm{C}(\mathrm{T})$ fracture mechanics specimen geometry. In Equation $6, E$ is the elastic Young's modulus, $C_{i}$ is the load-line crack opening elastic compliance and $B_{e}$ is the specimen effective thickness calculated by: 


$$
B_{e}=B-\left(B-B_{n}\right)^{2} / B
$$

Equation 7

where $B$ is the specimen full thickness and $B_{n}$ is the net thickness between the side grooves.

Once the $J R$ curve is generated and the exclusion lines (which are parallel to the blunting line with $0.1 \mathrm{~mm}$ and $\Delta a_{\max }$ offset) are constructed, a line of best fit must be made to the valid data points which fall in between the exclusion lines. The intersection between the $0.2 \mathrm{~mm}$ offset blunting line and the line of best fit to the valid data points can be taken as the $J_{I C}$ fracture toughness value (also known as $J_{0.2 B L}$ ). Finally, it must be ensured that the obtained $J_{I C}$ value is smaller than the maximum allowable $J$ value, $J_{\max }$, which can be calculated from the smaller of those given in Equation 8 and Equation 9.

$$
\begin{array}{cc}
J_{\max }=\left(W-a_{0}\right) \frac{\left(\sigma_{U T S}+\sigma_{Y}\right)}{40} & \text { Equation 8 } \\
J_{\max }=B \frac{\left(\sigma_{U T S}+\sigma_{Y}\right)}{40} & \text { Equation 9 }
\end{array}
$$

\section{Material Characterisation Test Results}

\subsection{Charpy Impact Tests}

Charpy impact tests were carried out following BS EN ISO 148-1:2010 using 10x10 mm² specimens with a $2 \mathrm{~mm}$ deep "V" notch [30]. Specimens were extracted with the notch tip located in the BM, HAZ and WM. Six tests (three specimens extracted from A1 and three from B1 plate) were performed on each material microstructure in $\mathrm{TC} 1$ at the ambient temperature. In TC2, three tests were performed on the BM, three on WM and six tests on the HAZ (three from the weld root and three from the weld cap). The Charpy impact tests in TC2 were conducted at $-20^{\circ} \mathrm{C}$. Finally, three tests were performed on each material microstructure in TC3 at the ambient temperature. A summary of the Charpy test details performed at different Test Centres is shown in Table 2. In total 39 Charpy impact tests (12 tests on BM, 15 on HAZ and 12 on WM) were performed on specimens extracted from 4 different welded plates (A1, A2, A3 and B1 plates). It must be noted that according to the Charpy impact test data on S355 in the literature, the test results obtained from temperatures of greater than $-30^{\circ} \mathrm{C}$ fall within the upper bound ductile shelf [31]. This suggests that the Charpy impact test results obtained at $-20^{\circ} \mathrm{C}$ in $\mathrm{TC} 2$ are comparable to those obtained at the ambient temperature in TC1 and TC3.

Table 2 - Test conditions and number of specimens for Charpy testing

\begin{tabular}{cccccc}
\hline Test Centre & BM & HAZ & WM & Temperature & Machine Maximum Energy \\
\hline TC1 & 6 & 6 & 6 & Ambient & $300 \mathrm{~J}$ \\
\hline TC2 & 3 & 6 & 3 & $-20^{\circ} \mathrm{C}$ & $300 \mathrm{~J}$ \\
\hline TC3 & 3 & 3 & 3 & Ambient & $750 \mathrm{~J}$ \\
\hline
\end{tabular}

According to ASTM E23 standard, the Charpy impact testing instruments are calibrated up to $80 \%$ of their maximum capacity. This means that for the $300 \mathrm{~J}$ machines (in TC1 and TC2), the results above $240 \mathrm{~J}$ impact energy are approximate [32]. This does not significantly influence the Charpy impact analysis in this project since these 
measurements are a qualitative means of comparing between materials. As such, a simple comparison is made between the results from different regions. Additionally, almost 2/3 of tests in the BM and HAZ did not result in a complete break of the specimen, which means that these may have had impact toughness above $300 \mathrm{~J}$ energy which were beyond the machine maximum capacity in TC1 and TC2.

The absorbed Charpy impact energy results for different welded plates obtained from various Test Centres are displayed in Figure 4. The average (i.e. mean) values are shown in Figure 4 and summarised in Table 3. Also included in Figure 4 are \pm 2 standard deviation ( $\pm 2 \mathrm{SD}$ ) bars indicating the level of scatter in test results. It can be seen in Figure 4 that the BM and WM have the highest and the lowest average impact energy, respectively, with the HAZ results falling in between them. Also seen in Figure 4 is a large experimental data scatter in the WM and HAZ test results. The scatter is low in the $\mathrm{BM}$, and increases further through the HAZ (approximately $\pm 25 \%$ from the mean value) and WM (approximately $\pm 30 \%$ from the mean value), showing the range in properties due to differential heating in these areas and subsequently variation in local properties ahead of the notch tip in the WM and HAZ specimens. Additionally, the mean Charpy impact energy decreases from the BM to the HAZ, and further decreases in the WM. The lack of complete breaks in the BM and HAZ means that the average results could be higher than is measured. This is particularly important for the BM which shows absorbed energies of just below 300J. If this large scatter extends above the $300 \mathrm{~J}$ mark, the mean value may be significantly higher than calculated.

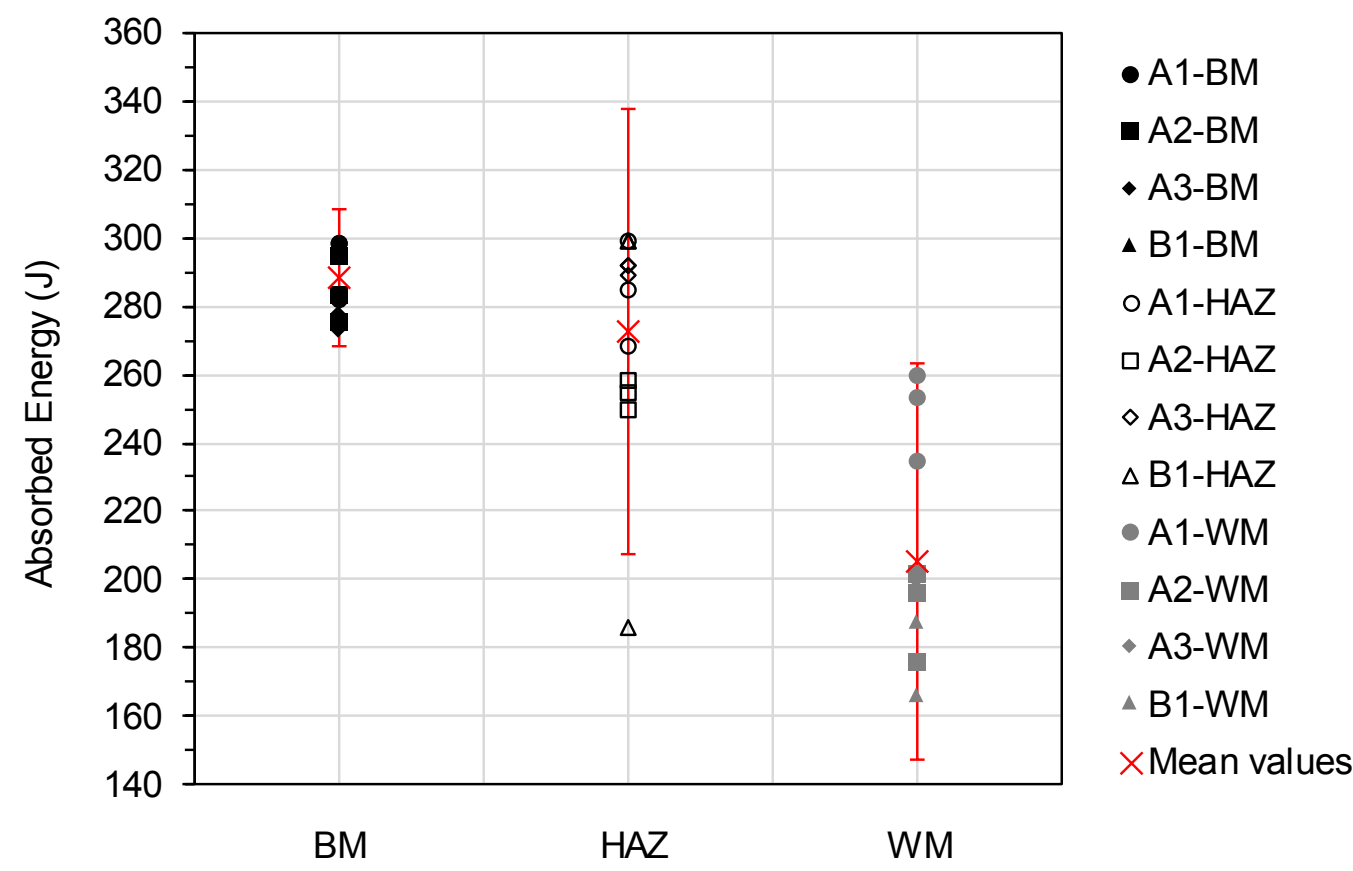

Figure 4 - Charpy impact test results for BM, HAZ and WM

Table 3 - The average absorbed Charpy impact energy, in joules $(\mathrm{J})$, for each plate

\begin{tabular}{ccccc}
\hline Plate & A1 & A2 & A3 & B1 \\
\hline BM & 293 & 285 & 277 & 298 \\
\hline HAZ & 284 & 254 & 291 & 261 \\
\hline
\end{tabular}




$\begin{array}{lllll}\text { WM } & 250 & 191 & 196 & 184\end{array}$

\subsection{Chemical Composition Analysis}

The chemical composition analysis was carried out following BS EN 10355 and ASTM E415 standards, which state a need to determine the percentage composition of the following elements: $\mathrm{Si}, \mathrm{Mn}, \mathrm{P}, \mathrm{Cu}, \mathrm{Ni}, \mathrm{Cr}, \mathrm{Mo}$ and $\mathrm{Sn}[33,34]$. For this analysis, the samples were tested using Optical Emission Spectroscopy (OES). The chemical composition analysis results for BM, HAZ and WM material in all four welded plates are given in Table 4. It can be seen in Table 4 that the HAZ and BM have the lowest proportion of $\mathrm{Si}$ and the $\mathrm{WM}$ has the lowest proportion of $\mathrm{Ni}$ and $\mathrm{Cu}$. The other elements have an approximately even distribution across the BM, HAZ and WM regions. Although analysis on the carbon content, $\mathrm{C}$, is not included in BS EN 10355 standard, the chemical composition analysis on the welded plates has shown that the average Carbon contents in $\mathrm{BM}, \mathrm{HAZ}$ and WM are 0.06, 0.07 and 0.08, respectively.

Table 4 - Chemical composition (\%) analysis results for different welded plates

\begin{tabular}{ccccccccc}
\hline Sample ID & Region & Si & Mn & P & Cr & Mo & Ni & Cu \\
\hline A1-BM & Base & 0.270 & 1.630 & 0.011 & 0.040 & 0.020 & 0.200 & 0.140 \\
\hline A1-HAZ & HAZ & 0.230 & 1.440 & 0.013 & 0.050 & 0.020 & 0.140 & 0.120 \\
\hline A1-WM & Weld & 0.330 & 1.620 & 0.013 & 0.030 & 0.020 & 0.040 & 0.070 \\
\hline A2-BM & Base & 0.269 & 1.480 & 0.010 & 0.027 & 0.017 & 0.335 & 0.234 \\
\hline A2-HAZ & HAZ & 0.268 & 1.469 & 0.009 & 0.027 & 0.019 & 0.313 & 0.228 \\
\hline A2-WM & Weld & 0.356 & 1.571 & 0.010 & 0.030 & 0.006 & 0.042 & 0.056 \\
\hline A3-BM & Base & 0.280 & 1.510 & 0.013 & 0.030 & 0.010 & 0.340 & 0.250 \\
\hline A3-HAZ & HAZ & 0.280 & 1.530 & 0.013 & 0.030 & 0.010 & 0.340 & 0.250 \\
\hline A3-WM & Weld & 0.350 & 1.620 & 0.013 & 0.020 & 0.010 & 0.060 & 0.070 \\
\hline B1-BM & Base & 0.240 & 1.530 & 0.013 & 0.140 & 0.020 & 0.380 & 0.200 \\
\hline B1-HAZ & HAZ & 0.220 & 1.560 & 0.018 & 0.100 & 0.020 & 0.430 & 0.220 \\
\hline B1-WM & Weld & 0.310 & 1.500 & 0.013 & 0.050 & 0.020 & 0.210 & 0.150 \\
\hline
\end{tabular}

\subsection{Hardness Tests}

Vickers macro and micro hardness tests were carried out following BS EN ISO 65071:1997 [35]. The weld macro section was prepared in accordance with EN ISO 17639 [36]. Hardness traverse specimens consisted of a slice of plate containing BM, HAZ and WM material, ground polished and etched to reveal the material microstructures, with a traverse along both weld root and cap regions. Each set of hardness tests was conducted along a straight line started in the BM and traversed through the HAZ, WM and the BM on the opposite side. The hardness test conditions at each Test Centre are summarised in Table 5. Figure 5 gives an example of the variation between A1 and B1 plates, with a completely different hardness profile for each plate. Plate A1 shows lower hardness values in the BM compared to the HAZ and WM whereas the lowest hardness values in plate B1 were found in the weld cap. Comparing the hardness profiles for A1 and B1 plates in Figure 5 it can be seen that although similar range of hardness values has been found in the WM region for both plates, the BM hardness range for B1 is higher than A1. An example of comparison between macro and micro hardness profiles is given in Figure 6 for plate A1. As seen in this figure macro and micro hardness results show good 
agreement where fluctuations in the WM can be attributed to local variations in material properties such as imperfections, heat input during welding or different weld beads. The average Vickers macro hardness values obtained from measurements along transverse direction in different welded plates are summarised in Table 6 for the WM and the BM on either side of the weld region. It can be seen in Table 6 that whilst the WM has only a small plate-to-plate deviation from the average hardness value, the BM exhibits a greater range ( $\pm 15 \%$ of the mean value), showing a wider scatter on what are often assumed to be identical plates.

Table 5 - Hardness test conditions at each test centre

\begin{tabular}{cccc}
\hline Test Centre & TC1 & TC2 & TC3 \\
\hline Macro Hardness & $30 \mathrm{~kg}$ & $10 \mathrm{~kg}$ & $10 \mathrm{~kg}$ \\
\hline Micro Hardness & $0.2 \mathrm{~kg}$ & $0.3 \mathrm{~kg}$ & $0.3 \mathrm{~kg}$ \\
\hline
\end{tabular}

Table 6 - Average Vickers macro hardness values for each plate, both in the weld region and the base on either side

\begin{tabular}{ccccccccc}
\hline & \multicolumn{2}{c}{ A1 } & \multicolumn{2}{c}{ A2 } & \multicolumn{2}{c}{ A3 } & \multicolumn{2}{c}{ B1 } \\
\hline & Cap & Root & Cap & Root & Cap & Root & Cap & Root \\
\hline Base & 167 & 160 & 232 & 222 & 210 & 216 & 199 & 200 \\
\hline Weld & 197 & 201 & 198 & 198 & 195 & 185 & 186 & 199 \\
\hline Base & 170 & 162 & 207 & 228 & 223 & 223 & 192 & 192 \\
\hline
\end{tabular}

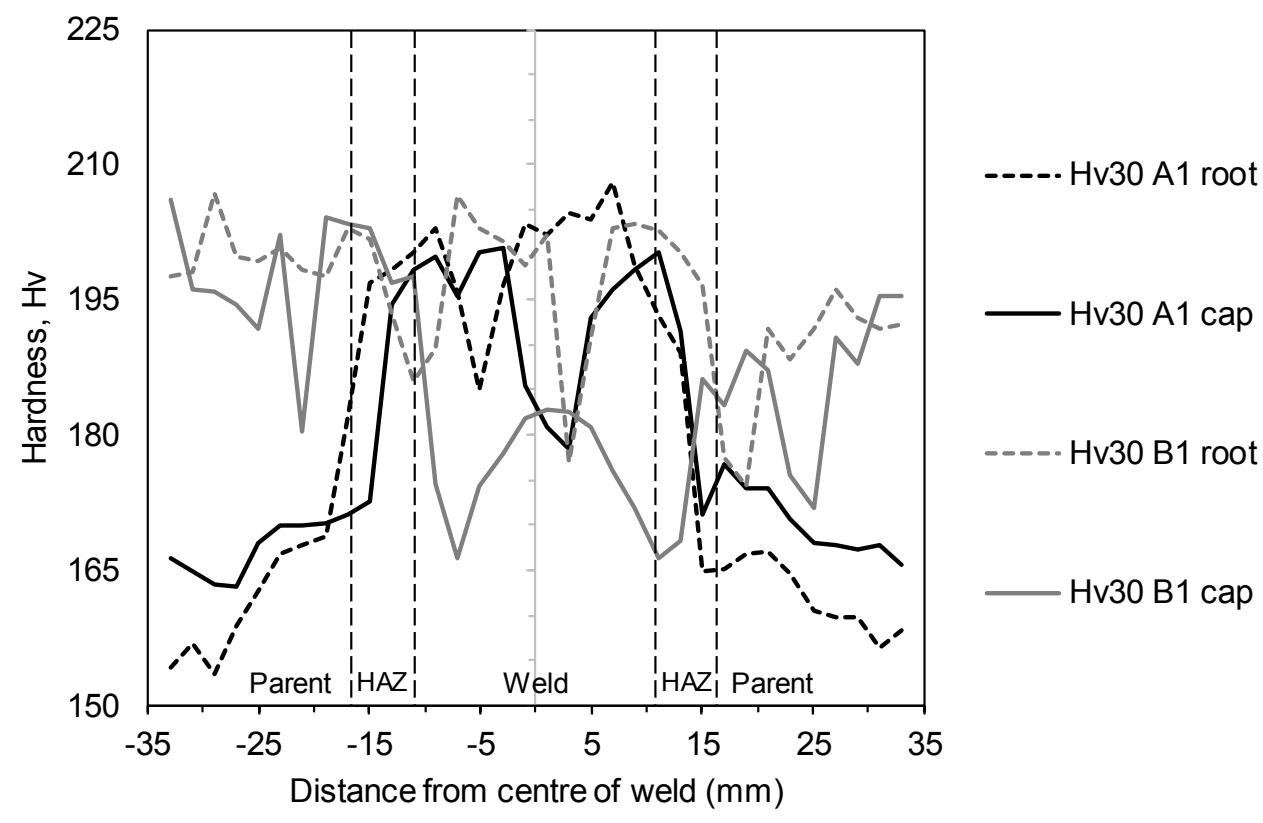

Figure 5 - Macro hardness comparison for plates A1 and B1 root and cap along transverse direction (plate A1 in black and plate B1 in grey) 


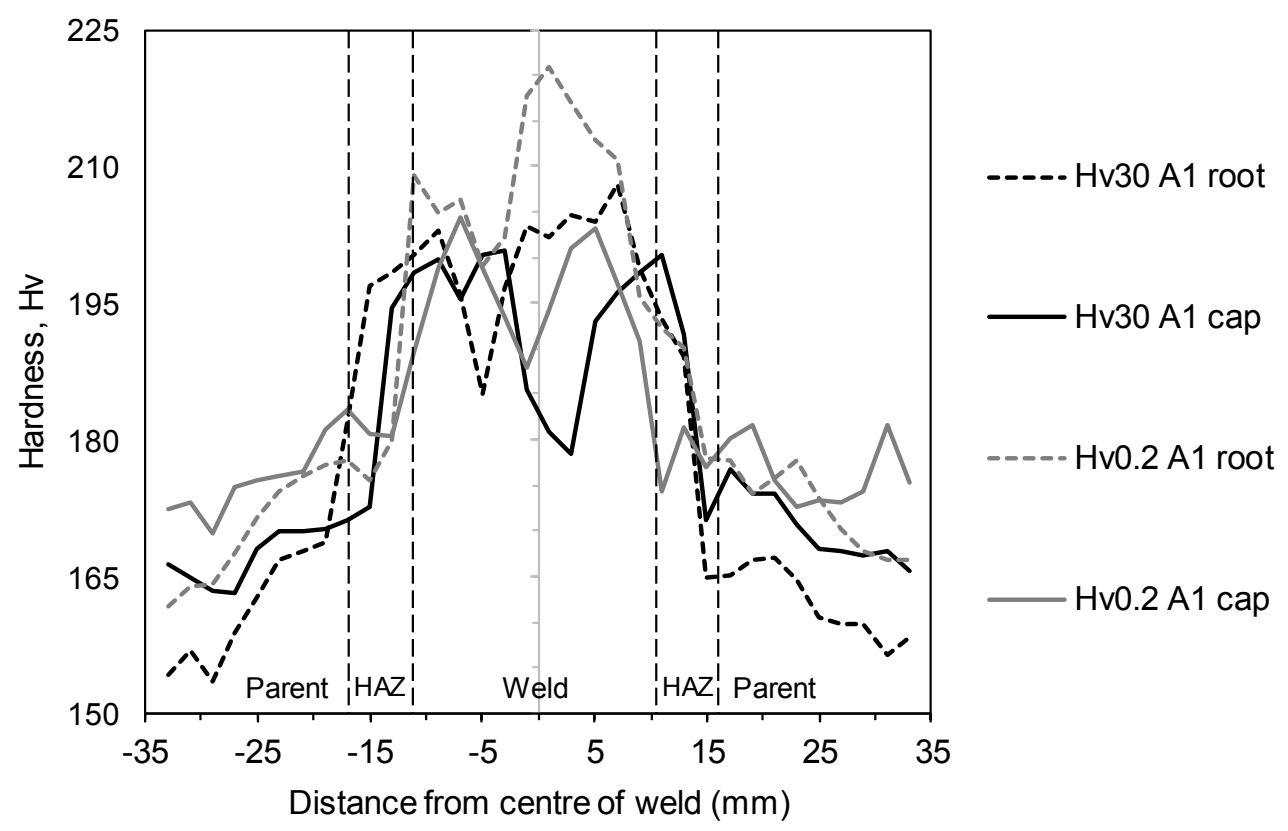

Figure 6 - Comparison of the macro and micro hardness test results for plate A1 along transverse direction (macro in black and micro in grey)

\subsection{Tensile Tests}

Two tensile specimen designs were used in this work:

i. $5 \mathrm{~mm}$ diameter 'standard' cylindrical gauge length (i.e. round bar) specimens manufactured from the BM.

ii. $5 \times 5 \mathrm{~mm}^{2}$ cross-weld specimens containing BM-HAZ-WM regions.

Three $5 \mathrm{~mm}$ diameter round bars and three $5 \times 5 \mathrm{~mm}^{2}$ cross-weld specimens were extracted from each welded plate and tested in TC1, TC2 and TC3. Tensile tests were conducted following BS EN ISO 6892-1:2009 [37]. All tests were performed under displacement control mode at the rate of $1.0 \mathrm{~mm} / \mathrm{min}$. The tests on tensile round bars were performed using standard clip-on extensometery for strain measurement purposes whereas the strain distributions on $5 \times 5 \mathrm{~mm}^{2}$ cross-weld specimens were measured on the outer surface using high resolution $3 \mathrm{D}$ digital image correlation (DIC) technique. It has been shown by various researchers that DIC is a suitable technique to measure local strain variations in tensile tests on cross-weld specimens (e.g. $[38,39])$. In tensile tests on round bars a 25 $\mathrm{mm}$ gauge length extensometer was used to provide up to $6 \%$ strain data, beyond which the extensometer was removed from the specimen and the test machine was controlled by the integral test machine displacement transducer. The use of DIC measurements for square cross-section specimens was necessary due to the small size of the HAZ region which was found to be approximately $3 \mathrm{~mm}$ in the welded plates examined in this study, hence too small for using standard clip gauge extensometery. The DIC gauge measures displacement by comparing the specimen surface pattern as the specimen is loaded and deforms. This allows the gauge software to derive the change in displacement between two targets, which the software tracks on the specimen surface. To provide a suitable pattern on the specimen for the video gauge to track, the specimen surface was lightly spray painted with a black and white speckle pattern. The local strain measurements from DIC tests were captured by extracting the surface averaged strain values at the mid-width 
of the BM, HAZ and WM regions, within a square size of around $2 \times 2 \mathrm{~mm}^{2}$. The temperature and humidity of the laboratories were maintained at $22^{\circ} \mathrm{C} \pm 2{ }^{\circ} \mathrm{C}$ and $50 \%$ relative humidity $\pm 10 \%$ during the tensile tests.

The tensile data were analysed subsequent to test completion and the elastic and plastic tensile properties from each data set were quantified. The elastic Young's modulus, yield stress, $\sigma_{Y}$, (taken as $0.2 \%$ proof stress) and UTS $\left(\sigma_{U T S}\right)$ for the BM, HAZ and WM obtained from $5 \times 5 \mathrm{~mm}^{2}$ cross-section DIC specimens are shown in Figure 7, Figure 8 and Figure 9, respectively. The mean value of each tensile property and the level of scatter observed in the data, which has been interpreted in terms of $\pm 2 \mathrm{SD}$, are shown in these figures and summarised in Table 7. It can be seen in Figure 7 and Table 7 that whilst the mean values of the Young's modulus are quite similar in the BM, HAZ and WM, relatively large scatters have been observed in BM and HAZ. It must be noted that due to the small deformation in the elastic region, the obtained values of the Elastic Young's modulus are sensitive to the resolution of the DIC system, therefore some inaccuracies might be encountered in elastic properties presented in Figure 7 and Table 7 . The average yield stress, observed in Figure 8 and Table 7, increases from BM through HAZ to the WM. Along with the lowest yield stress, the BM has the highest scatter of results, consistent with the high scatter in hardness values. An example of the BM, HAZ and WM tensile curves obtained from a $5 \times 5 \mathrm{~mm}^{2}$ cross-section DIC specimen is given in Figure 10. As seen in this figure, a clear increasing trend from BM through HAZ to the WM can be observed in the hardening behaviour of the material, which is consistent with the variation observed in the Carbon contents in section 4.2. It must be noted that although Figure 10 shows the strain variation for each material microstructure subjected to the same load, it does not reflect the real energy contribution to the deformation process. This is due to the fact that because of three distinct material microstructures (i.e. BM, WM and HAZ) in the gauge region, which have different sizes, the full deformation at the gauge section cannot be attained by all material microstructures. This is because once local yielding occurs in the material microstructure with lower yield strength, the surrounding material with higher yield strength forms a constraint around the softer material and as a result of this biaxial stresses develop in the region [38]. However, it has been shown and discussed in [38] that the percentage error between real proof stress values and those calculated from global stress is less than $8 \%$, which can be considered low enough to produce acceptable indicative values of yield stress for different material microstructures from DIC tests performed in this study. Further tests on small scale specimens with uniform material microstructure will be conducted in future work to examine potential limitations of the DIC measurement technique on cross-weld specimens.

As seen in Figure 9, there was only one test with the UTS and failure occurring in the $\mathrm{HAZ}$ region whilst the rest of the cross-weld specimens failed in the BM or WM region. There was approximately the same number of failures in the BM as in the WM, showing that these are the two regions with lower tensile strain at failure compared to the HAZ. However, perhaps the larger size of these regions along the gauge length also influenced this increase in failures. In cross-weld specimens, the majority of the strain is experienced in the lowest strength material. However, it is usually possible to obtain at least the $0.2 \%$ proof stress for all materials in the cross-weld specimen, depending on the strength mismatch. It is also worth noting that the UTS obtained from this type of specimen will be for the lowest strength material microstructure, hence why the majority of failures/UTS data points (see Figure 9) are in the BM and WM. Finally observed in Figure 9 and Table 
7 is that the mean UTS value in the WM was found larger than the BM. This observed trend in the UTS is consistent with the increasing yield stress trend from BM to WM seen in Figure 8. Also seen in Figure 8 is that the mismatch ratio, defined as $M=\sigma_{Y, W M} / \sigma_{Y, B M}$ where $\sigma_{Y, W M}$ is the yield stress of the WM and $\sigma_{Y, B M}$ is the yield stress of the BM, is on around 1.2 for the welded plates examined in this study indicating slightly overmatched condition.

The tensile properties obtained from $5 \mathrm{~mm}$ diameter BM round bars are summarised in Table 8 for each of the four plates examined in this project. It can be seen in Table 8 that the lowest and the highest plastic properties have been found in A1 and A2 plate, respectively, with $\mathrm{A} 3$ and $\mathrm{B} 1$ plate plastic properties falling close to each other and in between the maximum and minimum range obtained from the other two plates. Comparing the BM tensile properties in Table 7 and Table 8 it can be seen that the elastic and plastic properties obtained from $5 \mathrm{~mm}$ diameter round bars are in relatively good agreement with those obtained from the BM region of the $5 \times 5 \mathrm{~mm}^{2}$ cross-section specimens. This confirms that the tensile properties generated using DIC technique are comparable to those obtained using clip gauge extensometry.

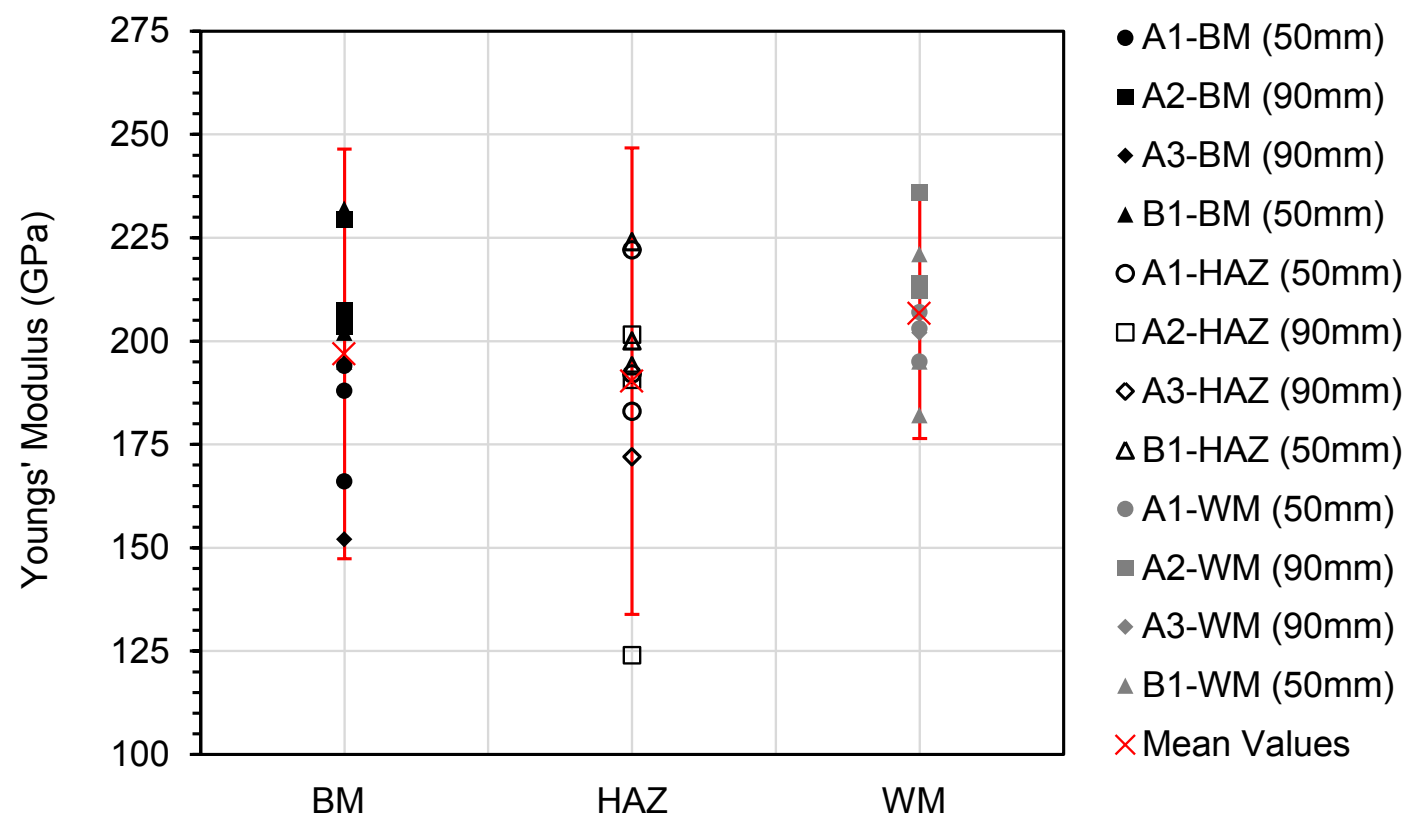

Figure 7 - Variation of the elastic Young's Modulus in the BM, HAZ and WM region of the DIC tested specimens 


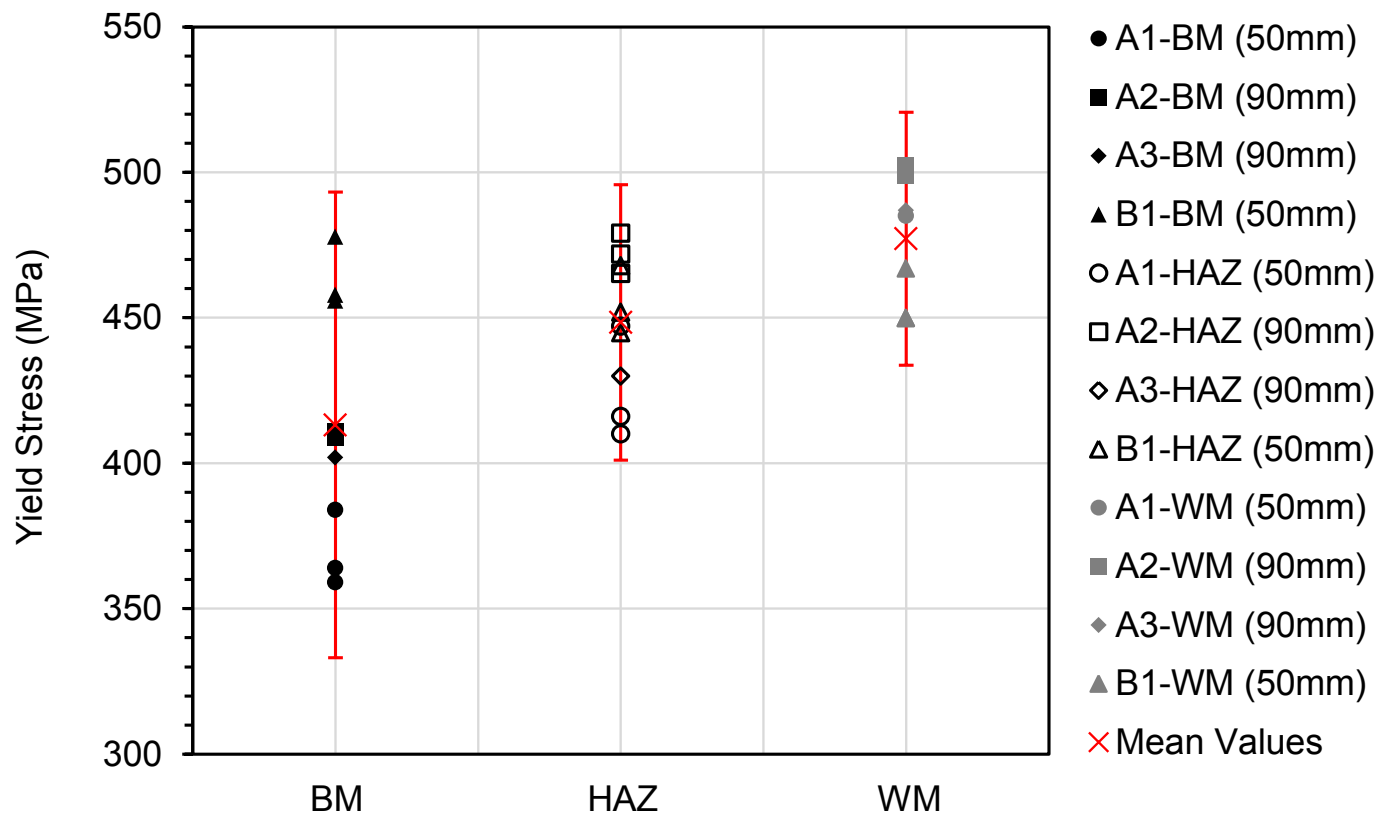

Figure 8 - Variation of the yield stress in the BM, HAZ and WM region of the DIC tested specimens 


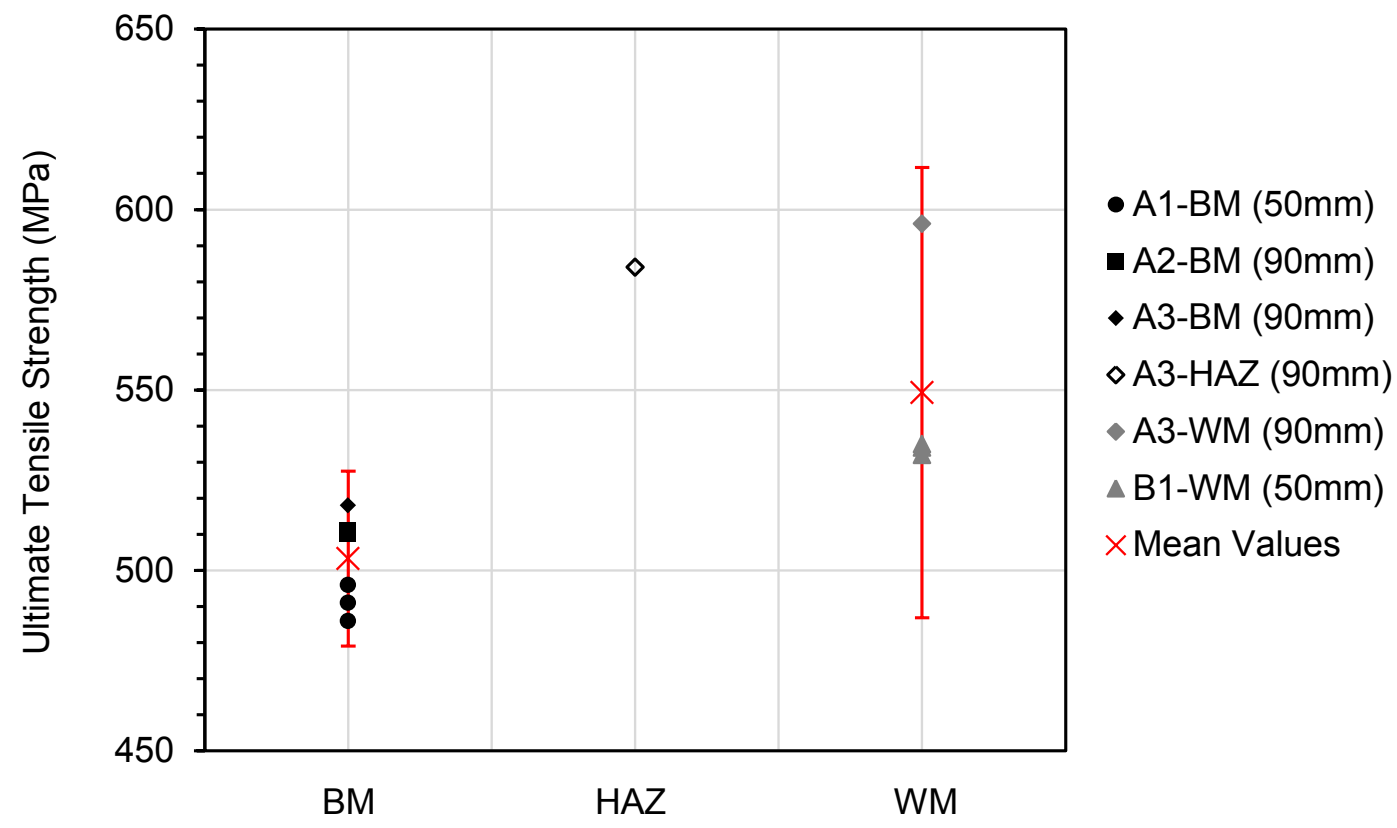

Figure 9 - Variation of the UTS in the BM, HAZ and WM region of the DIC tested specimens

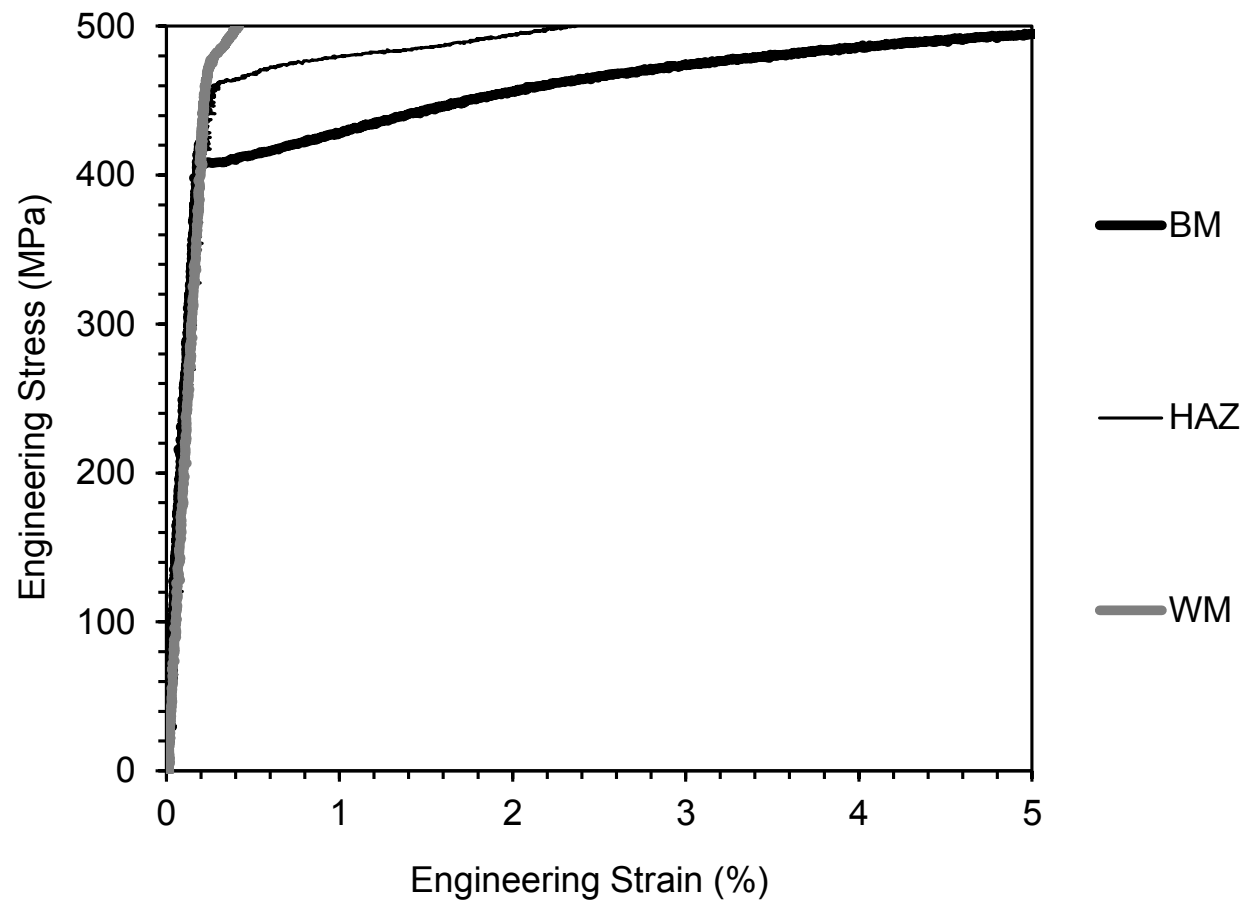

Figure 10 - Comparison of the BM, HAZ and WM tensile curves obtained from a $5 \times 5$ $\mathrm{mm}^{2}$ cross-section DIC specimen tested in TC2 
Table 7 - A summary of tensile test results from $5 \times 5 \mathrm{~mm}^{2}$ cross-section DIC specimens

\begin{tabular}{cccc}
\hline Material & $\begin{array}{c}\text { Young's Modulus } \\
(\mathbf{G P a})\end{array}$ & $\begin{array}{c}\text { Yield Stress } \\
\text { (MPa) }\end{array}$ & $\begin{array}{c}\text { UTS } \\
\text { (MPa) }\end{array}$ \\
\hline BM & $197 \pm 50$ & $413 \pm 80$ & $503 \pm 24$ \\
\hline HAZ & $190 \pm 56$ & $448 \pm 47$ & 585 \\
\hline WM & $207 \pm 30$ & $477 \pm 43$ & $549 \pm 62$ \\
\hline
\end{tabular}

Table 8 - A summary of tensile test results from $5 \mathrm{~mm}$ diameter round bars

\begin{tabular}{cccc}
\hline Material & $\begin{array}{c}\text { Young's Modulus } \\
\text { (GPa) }\end{array}$ & $\begin{array}{c}\text { Yield Stress } \\
\text { (MPa) }\end{array}$ & $\begin{array}{c}\text { UTS } \\
\text { (MPa) }\end{array}$ \\
\hline BM-A1 & $214 \pm 8$ & $383 \pm 12$ & $478 \pm 14$ \\
\hline BM-A2 & $211 \pm 13$ & $524 \pm 11$ & $603 \pm 8$ \\
\hline BM-A3 & $216 \pm 11$ & $440 \pm 86$ & $566 \pm 84$ \\
\hline BM-B1 & $212 \pm 12$ & $440 \pm 14$ & $548 \pm 2$ \\
\hline BM-Overall & $213 \pm 10$ & $447 \pm 112$ & $549 \pm 102$ \\
\hline
\end{tabular}

\subsection{Fracture Toughness Tests}

Fracture toughness tests were conducted following the guidelines provided in the British Standards which are in agreement with ESIS and ASTM standards and are commonly used in industry $[27,29,40]$. For the compliance technique, these standards refer to the technique specified in ASTM E1820 [27]. In C(T) and SEN(B) fracture toughness tests on WM the crack tip was located at the centre of the weld region, whereas in the HAZ samples the crack tip was located at the centre of the HAZ region (see [19]). It must be noted that in this test programme the high constraint $\mathrm{C}(\mathrm{T})$ and relatively low constraint SEN(B) geometries which are recommended by ASTM E1820 [27] were employed for testing. However, for comparison purposes further tests will be conducted on other low constraint specimen geometries such as Single Edge Notched Tension, SEN(T), in future work $[41,42]$. The tests were performed using the single specimen compliance technique in TC3 whist multiple-specimen approach was employed by TC1. The experimental details and fracture toughness test results from two different approaches are described and discussed below.

\subsubsection{Single Specimen Compliance Technique}

Fracture toughness tests using single specimen compliance technique were performed on C(T) specimens according to BS 7448 and ASTM E1820 standards by TC3 [27, 29]. Six stepped notched $\mathrm{C}(\mathrm{T})$ specimens were machined from A3 welded plate with two specimens for each material microstructure (BM, HAZ and WM). The specimens were firstly pre-fatigue cracked to approximately $0.5 \mathrm{~W}$ using $K$-decreasing approach. This was done to introduce a sharp crack tip into the laboratory scale specimens without allowing a significant plastic zone size being developed ahead of the starter crack tip. After precracking, the $25 \mathrm{~mm}$ thick $\mathrm{C}(\mathrm{T})$ specimens were side grooved by $0.1 B$ (i.e. $10 \%$ of the total thickness) at each side to further increase the constraint level in the test specimens 
and attain plane strain dominant conditions in the samples. A servo-hydraulic machine from INSTRON with the load cell capacity of $\pm 100 \mathrm{kN}$ was used for pre-cracking and the fracture toughness tests. The $\mathrm{C}(\mathrm{T})$ specimens tested by TC3 are denoted A3-BM-1, A3BM-2, A3-HAZ-1, A3-HAZ-2, A3-WM-1 and A3-WM-2 and their dimensions are summarised in Table 9. As seen in this table, all specimens had the width, total thickness and net thickness of approximately $W=50 \mathrm{~mm}, B=25 \mathrm{~mm}$ and $B_{n}=20 \mathrm{~mm}$, respectively. Also included in this table are the initial crack length, $a_{0}$, at the beginning of the test (i.e. after pre-fatigue cracking), the final crack length, $a_{f}$, at the end of the test and the maximum allowable crack extension, $\Delta a_{\max }$, calculated for each specimen using Equation 4. Note that $a_{0}$ and $a_{f}$ values reported in Table 9 were measured on the fracture surface after specimen break open subsequent to test completion.

Fracture toughness tests were performed by applying sequences of loading and partial unloading at specified intervals. The load and load line displacement (LLD) data, measured using a clip gauge attached to the crack mouth of the specimen, were recorded during the tests. The tests were performed under LLD control mode with 5 minutes hold time followed by $20 \%$ unloading at each peak load. The unloading slopes, which are linear and independent of prior plastic deformation, were used to estimate the instantaneous crack length at each unloading increment using the elastic compliance relationships in Equation 5 and Equation 6. All tests were performed at room temperature with the loading/unloading rate of $1.0 \mathrm{~mm} / \mathrm{min}$ for BM specimens and $0.5 \mathrm{~mm} / \mathrm{min}$ for HAZ and WM specimens, and a LLD increment of $0.125 \mathrm{~mm}$ for all specimens.

The fracture toughness $J R$ curves obtained from these tests are shown in Figure 11 and the $J_{I C}$ results are summarised in Table 9. The $J$ fracture mechanics parameter in all tests was calculated using Equation 2 assuming that for the mismatch ratio $M$ of close to 1, the value of $\eta$ is approximately the same for the BM and weld specimens [43]. This indicates that for the slightly overmatched welded specimens examined in this study the mismatch ratio does not have any noticeable effect on the driving force calculations. Also included in Figure 11 are the blunting line and exclusion lines, which were described in Section 3, the slope of which was calculated using Equation 3 by employing the material specific average $\sigma_{U T S}$ values specified in Table 7. Note that the lines plotted in Figure 11 are based on BM for demonstration purposes and material specific properties were employed to reconstruct the exclusion lines for the HAZ and WM. It can be seen in Figure 11 that for a given value of crack extension, $\Delta a$, the highest and the lowest values of the fracture mechanics parameter $J$ were observed in the HAZ and WM, respectively. This means that the amount of energy required to propagate the crack is greater in HAZ compared to WM, which is consistent with the observed trend in $J_{I C}$ fracture toughness values in Table 9. It can be seen in Table 9 that the average $J_{I C}$ values obtained from the tests on C(T) specimens are 0.88 MPam, 1.41 MPam and 0.51 MPam for the BM, HAZ and WM, respectively. The corresponding material microstructure specific $K_{I C}$ values, calculated based on the elastic condition using Equation 1 and by considering plane strain conditions, are $435 \mathrm{MPa} \sqrt{\mathrm{m}}, 542 \mathrm{MPa} \sqrt{\mathrm{m}}$ and $341 \mathrm{MPa} \sqrt{\mathrm{m}}$ for the BM, HAZ and WM, respectively. These values are similar though marginally higher than those reported in the literature for other grades of S355 steel [10-16, 44].

Also seen in Figure 11 is that for the slightly overmatched welded specimens the $J R$ curves and consequently fracture toughness values for the WM are lower than the BM. This observation is consistent with similar studies on overmatched welded specimens e.g. [45] and is associated with the fact that in a slightly overmatched weld, less extensive 
yielding occurs at the crack tip which results in an increase in the crack tip constraint level hence a lower $J R$ curve behaviour compared to the BM [45]. Further seen in Figure 11 is that a relatively good repeatability can be observed for generation of the $J R$ curves for the $\mathrm{BM}$ and the $J R$ curves from both data sets fall upon each other. Although the $J R$ curves for the data sets on the WM and HAZ fall close to each other, the slight discrepancies between the two data sets may be associated with the material microstructure around the crack tip. For the WM specimens the crack tip was located in different weld beads and for the HAZ specimens the initial crack tip was located in the middle of the HAZ region but as the crack started to propagate the crack tip moved toward the course or fine grain region. It must be also noted that the recommended $\eta$ factor solutions specified in standards (see3) for a homogenous material have been employed in this work to analyse the fracture toughness data on the WM and HAZ. Considering that the $\eta$ values for overmatched weldments are slightly different to homogenous materials [46], this might have introduced a small slight uncertainty in the $J R$ curves obtained from WM and HAZ specimens.

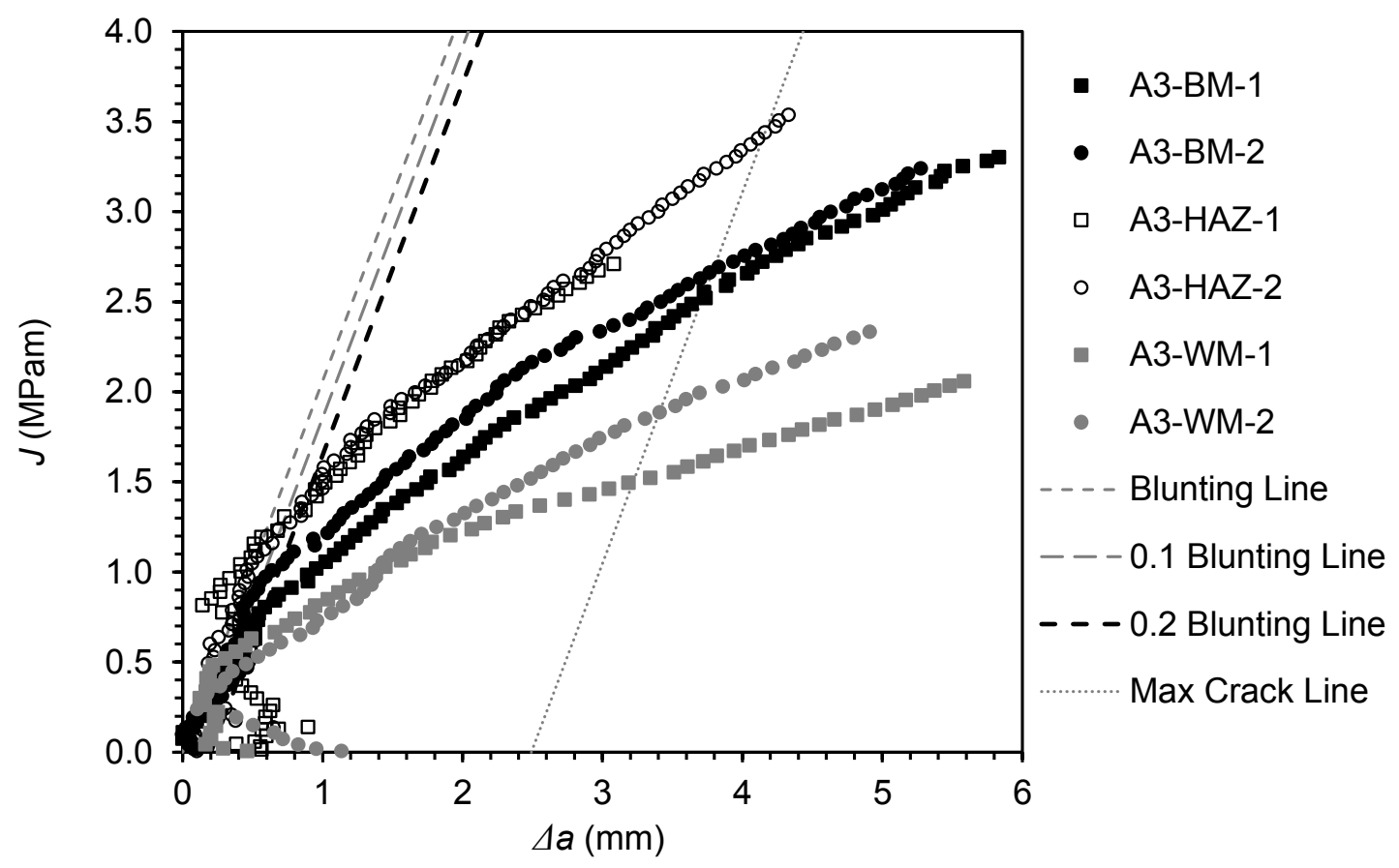

Figure 11 - Fracture toughness $J R$ curves generated using single specimen compliance technique in TC3 from A3 plate

Table 9 - A summary of fracture toughness test results and specimen dimensions (* - indicative estimation value)

\begin{tabular}{|c|c|c|c|c|c|c|c|c|}
\hline $\begin{array}{l}\text { Specimen } \\
\text { ID }\end{array}$ & Geometry & $\begin{array}{c}W \\
(\mathrm{~mm})\end{array}$ & $\begin{array}{c}B \\
(\mathbf{m m} \\
)\end{array}$ & $\begin{array}{c}B_{n} \\
(\mathbf{m m} \\
)\end{array}$ & $\begin{array}{c}a_{0} \\
(\mathbf{m m})\end{array}$ & $\begin{array}{c}\begin{array}{c}a_{f} \\
(\mathbf{m m}\end{array} \\
)\end{array}$ & $\begin{array}{l}\Delta a_{\max } \\
(\mathrm{mm})\end{array}$ & $\begin{array}{c}J_{I C} \\
\text { (MPam } \\
\text { ) }\end{array}$ \\
\hline A1-BM-1 & \multirow{2}{*}{ SEN(B) } & 45.08 & 22.63 & 22.63 & 23.52 & 26.30 & 2.16 & \multirow{2}{*}{$0.8^{*}$} \\
\hline A1-BM-2 & & 45.10 & 22.60 & 22.60 & 23.33 & 26.04 & 2.18 & \\
\hline
\end{tabular}




\begin{tabular}{|c|c|c|c|c|c|c|c|c|}
\hline A1-BM-3 & & 45.09 & 22.60 & 22.60 & 23.32 & 23.89 & 2.18 & \\
\hline B1-BM-1 & & 45.09 & 22.58 & 22.58 & 22.89 & 25.67 & 2.22 & \\
\hline B1-BM-2 & & 45.10 & 22.63 & 22.63 & 23.05 & 25.16 & 2.20 & \\
\hline B1-BM-3 & & 45.08 & 22.62 & 22.62 & 23.26 & 26.69 & 2.18 & \\
\hline A3-BM-1 & \multirow{2}{*}{$C(\mathrm{~T})$} & 49.95 & 25.01 & 20.46 & 25.22 & 31.03 & 2.47 & 0.73 \\
\hline A3-BM-2 & & 50.08 & 25.07 & 20.25 & 24.98 & 29.97 & 2.51 & 1.02 \\
\hline A1-HAZ-1 & \multirow{6}{*}{ SEN(B) } & 45.09 & 22.54 & 22.54 & 23.42 & 26.04 & 2.17 & \multirow{6}{*}{$0.4^{*}$} \\
\hline A1-HAZ-2 & & 45.07 & 22.59 & 22.59 & 23.80 & 25.24 & 2.13 & \\
\hline A1-HAZ-3 & & 45.11 & 22.55 & 22.55 & 22.98 & 25.25 & 2.21 & \\
\hline B1-HAZ-1 & & 45.10 & 22.60 & 22.60 & 23.32 & 26.15 & 2.18 & \\
\hline B1-HAZ-2 & & 45.11 & 22.56 & 22.56 & 23.44 & 25.29 & 2.17 & \\
\hline B1-HAZ-3 & & 45.10 & 22.56 & 22.56 & 23.50 & 27.09 & 2.16 & \\
\hline A3-HAZ-1 & \multirow{2}{*}{$\mathrm{C}(\mathrm{T})$} & 50.00 & 24.97 & 20.17 & 25.68 & 30.67 & 2.43 & 1.35 \\
\hline A3-HAZ-2 & & 49.92 & 24.99 & 20.18 & 26.24 & 31.24 & 2.37 & 1.46 \\
\hline A1-WM-1 & \multirow{6}{*}{ SEN(B) } & 45.10 & 22.62 & 22.62 & 24.16 & 26.68 & 2.09 & \multirow{6}{*}{$0.7^{*}$} \\
\hline A1-WM-2 & & 45.10 & 22.63 & 22.63 & 24.18 & 25.04 & 2.09 & \\
\hline A1-WM-3 & & 45.11 & 22.63 & 22.63 & 23.98 & 25.89 & 2.11 & \\
\hline B1-WM-1 & & 45.11 & 22.60 & 22.60 & 23.28 & 26.04 & 2.18 & \\
\hline B1-WM-2 & & 45.10 & 22.61 & 22.61 & 23.41 & 24.75 & 2.17 & \\
\hline B1-WM-3 & & 45.11 & 22.61 & 22.61 & 23.45 & 26.91 & 2.17 & \\
\hline A3-WM-1 & \multirow{2}{*}{$\mathrm{C}(\mathrm{T})$} & 50.08 & 25.04 & 19.93 & 26.33 & 31.33 & 2.37 & 0.60 \\
\hline A3-WM-2 & & 49.98 & 25.06 & 19.95 & 25.30 & 30.29 & 2.47 & 0.42 \\
\hline
\end{tabular}

\subsubsection{Multiple-Specimen Approach}

Fracture toughness tests using multiple-specimen approach were conducted on SEN(B) specimens by TC1 following BS $7448^{26,27}$. Nine specimens were extracted from each of A1 and B1 welded plates with three specimens from each of the BM, HAZ and WM material microstructures. The dimensions of SEN(B) specimens are specified in Table 9. As seen in this table, all SEN(B) specimens were $22.5 \mathrm{~mm}$ thick and $45 \mathrm{~mm}$ wide. A large thickness value was chosen for SEN(B) specimens to attain plane strain dominant conditions in these samples. In order to construct a $J R$ curve using multiple specimen approach a minimum of six valid tests are required. Therefore, the results from TC1 were used to estimate an indicative value of fracture toughness for comparison with those obtained from TC3. It is worth noting that $J R$ curves are not part of BS 7448-1:1991, but are covered in BS 7448-4:1997 [29].

All SEN(B) fracture toughness test specimens were pre-fatigue cracked to a nominal crack length-to-width ratio of $a_{0} / W=0.52$ using $K$-decreasing approach. Testing was carried out using a $250 \mathrm{kN}$ Schenck-Trebel servo-electric machine. All tests were stopped post $J_{\max }$ (i.e. $J$ value at the maximum load) at differing amounts of ductile crack growth. After testing, specimens were heat tinted and broken open to measure the initial and final crack lengths, which have been summarised in Table 9. The applied force and LLD, measured using a linear variable differential transformer (LVDT), were recorded during the tests. The displacement from the LVDT was corrected to subtract the extraneous elastic displacement arising from the loading fixtures and test machine following the 
guidelines provided in BS 7448 [29]. All tests were conducted at room temperature with the loading rate of $1.0 \mathrm{~mm} / \mathrm{min}$.

$J$ values were calculated at the end of each test and plotted against ductile crack growth as seen in Figure 12. It can be observed in this figure that although a consistent $J R$ trend is apparent for the $\mathrm{WM}$ from $\mathrm{A} 1$ and $\mathrm{B} 1$ plates, some variation in $J R$ trends can be observed for the BM and HAZ specimens extracted from A1 and B1 plates. With the $J R$ curve constructed in Figure 12, indicative $J_{I C}$ values can be found by plotting the line of best fit to six data points available for each material. The estimated values of $J_{I C}$ from multiple-specimen approach are summarised in Table 9. As seen in Figure 12 the data points obtained from multi-specimen approach are sparse near the 0.2 offset line, therefore the confidence in the estimated fracture toughness values from this approach is less than the results presented from the single specimen approach. It can be seen in Table 9 that some discrepancy can be observed in the values obtained from these two specimen geometries due to different constraint level and testing approach. Moreover, not shown here for brevity it has been found that the plate specific values of UTS change the estimated $J_{I C}$ insignificantly and lead to similar indicative values of fracture toughness.

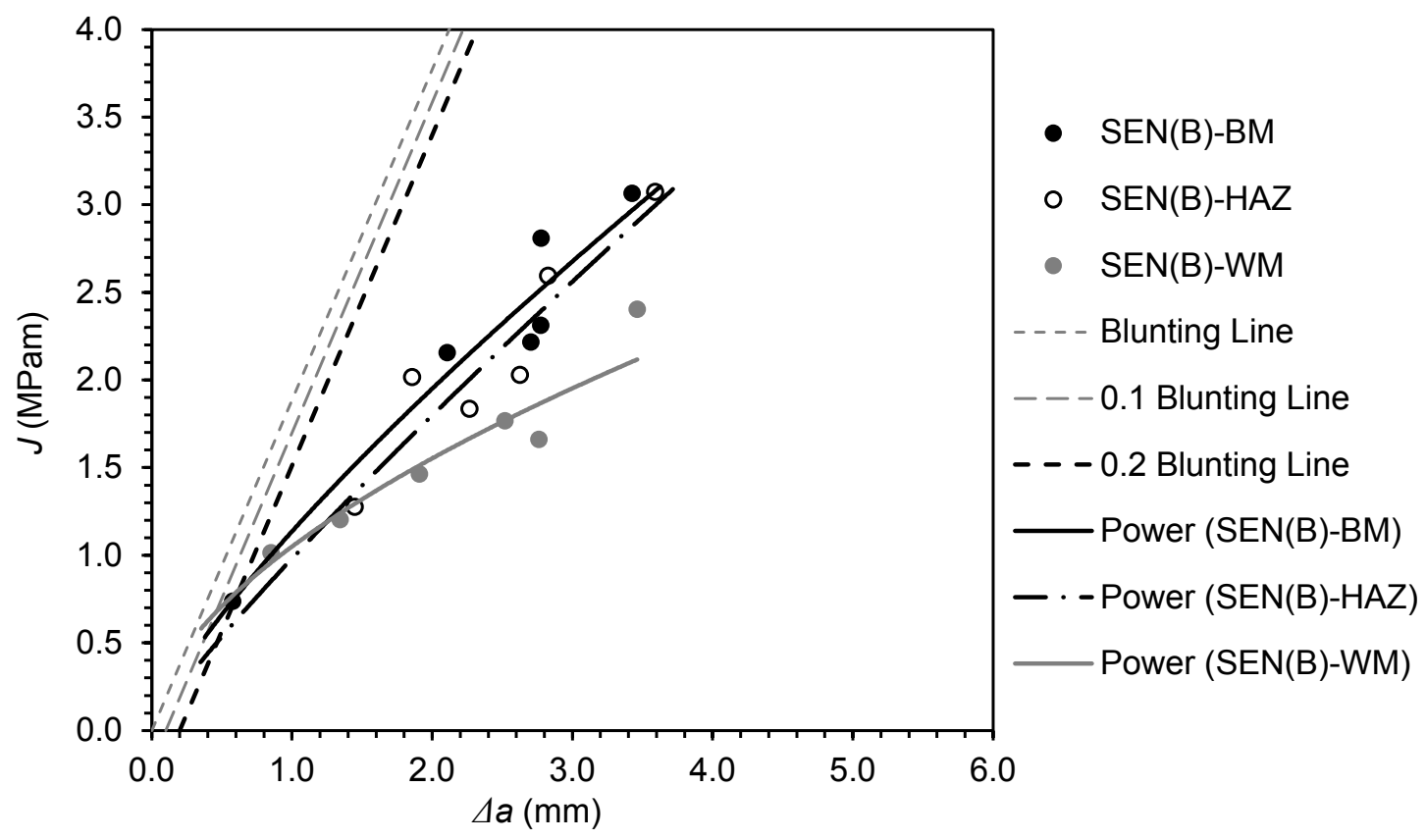

Figure 12 - Indicative fracture toughness results from SEN(B) tests performed in TC1

$J$ at the first attainment of maximum force plateau (i.e. $J_{\max }$ ) values for each of the SEN(B) tests performed on BM, HAZ and WM specimens are plotted in Figure 13. Also included in this figure are the average $J_{\max }$ values and \pm 2 SD bars. It can be seen in Figure 13 that the average $J_{\max }$ value for WM is significantly lower than the mean value for BM. Furthermore, although there is significantly more scatter in the HAZ fracture toughness results, the average $J_{\max }$ value for the HAZ material falls in between the WM and BM. Finally seen in Figure 13 is that the obtained $J_{\max }$ values for the BM and WM specimens extracted from both plates (i.e. A1 and B1) are similar to each other. 


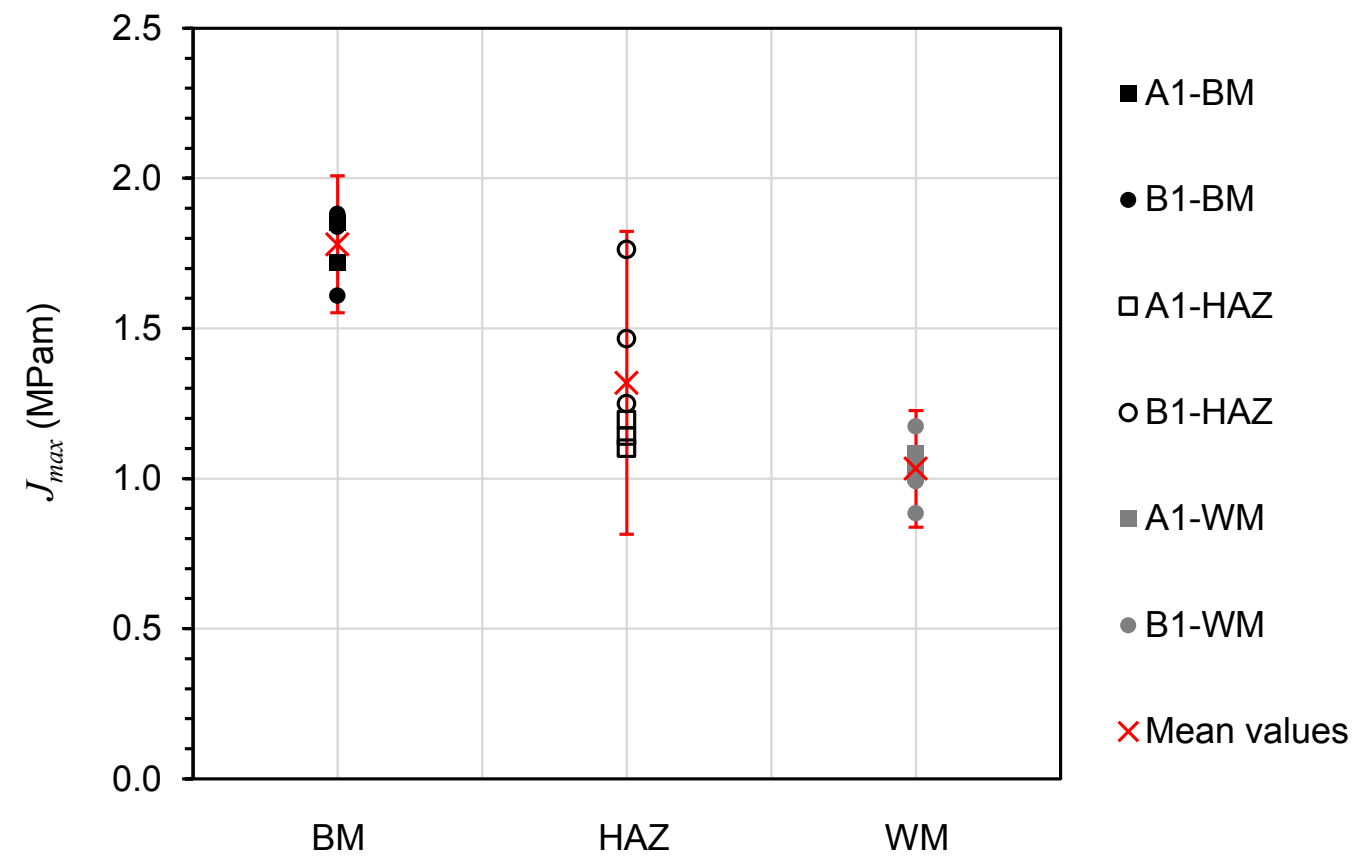

Figure $13-J_{\max }$ values obtained from $\mathrm{SEN}(\mathrm{B})$ specimens extracted from A1 and B1 plates

\section{Discussion}

The BM examined in the SLIC project shows hardness values ranging from $160 \mathrm{Hv}$ to $232 \mathrm{Hv}$ accompanied by yield stress ranging from $359 \mathrm{MPa}$ to $478 \mathrm{MPa}$. The majority of tensile failures occurred in the BM with ultimate tensile strengths ranging from $486 \mathrm{MPa}$ to $518 \mathrm{MPa}$. On all accounts concerning mechanical properties, the BM agrees well with the ranges supplied in the literature $[3,4]$. The BM fracture toughness obtained from the SLIC project is higher than in literature, which may be partially due the method of plate manufacture or the thickness of the test specimens examined in this project. There is a large scatter in the mechanical and fracture properties of S355 weldments from literature, which is consistent with this study, where the average scatter in results was $\pm 20 \%$, and the largest scatter was generally observed in the HAZ. The large scatter is due to the very generic nature of S355 as a category of steel, as evidenced by the differences in chemical composition of each plate and can be further seen in the mechanical properties. Another important observation made using the results from this project is that a consistent increase in the yield stress and hardness results can be seen from BM to WM. This means that the yield strength and hardness are proportional to each other $\left(\mathrm{Hv} \propto \sigma_{\mathrm{Y}}\right)$ as suggested in the literature [47]. It must be noted that in mechanical testing the yield stress trends may be considered more reliable due to a volume-averaged (i.e. using extensometer) or surfaceaveraged (i.e. using DIC) strain measurements, whereas the hardness measurement is a very localised result which can be influenced by material inhomogeneity, surface finish and roughness.

The obtained results from the SLIC project have revealed that the Charpy impact test results follow the same trend as the $J_{\max }$ with the highest average value found for the BM, lowest value for the WM and intermediate value for the HAZ. This is a reverse trend compared to yield stress results from BM, HAZ and WM materials. This indicates that in offshore monopile weldments, with slightly overmatched condition, the material 
microstructure with lower yield stress requires a higher energy, due to extensive plastic deformation, to initiate a crack. A clear conclusion from the SLIC project test results is that for the slightly overmatched welded plates examined in this project the WM has the highest average yield stress and the lowest average fracture toughness, although this simply depends on the filler metal used and strength mismatch. When considering these with respect to the results published in the literature, it is noted that the mechanical properties of the welds are dominated by the mismatch factor [48]. Overmatched welds show an increase in residual stresses compared to undermatched (or matched) welds [39, 49] which is consistent with the results from this study. Fracture toughness dependency on weld mismatch factor is inconclusive, with an increase in mismatch factor showing a slightly increased fracture toughness in some studies $[48,50]$, deemed to be due to base metal variation (which is not present in this study) [48, 51].

As seen in Figure 11 a decreasing trend in $\Delta a$ was observed at early stages of tests on HAZ and WM specimens where the load levels were relatively low. This may indicate that tensile residual stresses from the welding process were present in HAZ and WM specimens, which led to overestimated values of instantaneous crack length from unloading compliance measurements at low load levels. However, as the load level increased the tensile residual stresses gradually washed out from the specimens because of the plastic strain development ahead of the crack tip. Therefore, an increasing crack extension trend was exhibited after the first few loading/unloading intervals in HAZ and WM specimens. Welding residual stresses are not expected to influence the fracture toughness values, which is identified at the point where significant plastic deformation has been developed ahead of the crack tip. However, these internal locked-in stresses can be as large as the yield stress, depending on the welding process and strength mismatch, at early stages of fracture toughness tests on the HAZ and WM specimens. Therefore, neutron diffraction residual stress measurements will be conducted on nominally identical specimens in future work to provide a more accurate interpretation of the $J R$ curves at early stages of fracture toughness tests.

\subsection{Material Properties Effects on Engineering Critical Assessment}

The thick-walled monopile foundation structures have little structural redundancy, so a reliable Engineering Critical Assessment (ECA), to perform failure assessment and predict the critical flaw size, and subsequently adapting an effective inspection plan is of fundamental importance to overall life-time prediction for these offshore structures. In offshore wind turbine monopiles, the cracks are most likely to initiate in the HAZ region and propagate into the BM. Alternatively, the crack initiation and growth may occur within the WM region in monopiles with as-welded condition if the welding quality is poor and large stress concentrations are available at the weld toe. This means that the large scatter in the mechanical and fracture properties of each of the BM, HAZ and WM materials needs to be carefully considered in ECA of monopiles. ECA is very sensitive to the input parameters, which mainly include fracture toughness and tensile properties. For engineering applications, conservative (but not overly conservative) estimates are recommended to use for ECA engineering calculations. However, with such a large scatter in input variables, it is important to ensure that the analyses provide a realistic estimate of structural integrity for offshore monopiles by employing appropriate upper/lower bound values in calculations. The SLIC project results show that even plates produced through the same method from the same manufacturer have scatter up to $\pm 25 \%$ 
in the Charpy impact energy results and the yield stress of the material, hence a great deal of care must be taken when undertaking ECA to ensure that the conclusions are appropriate.

\subsection{Case Study}

An offshore wind turbine monopile structure of $5 \mathrm{~m}$ outer diameter and $90 \mathrm{~mm}$ wall thickness is known to have been exposed to corrosion fatigue damage. During an extreme weather event a cyclic nominal stress range of $200 \mathrm{MPa}$ was measured at the mudline. Knowing that the inspection frequency needs to increase as the crack length approaches its critical value, below which the structure is safe to operate, the critical flaw size can be estimated using R6 Level III failure assessment procedure [52]. In Level III failure assessment diagram, $K_{r}$ is plotted against $L_{r}$ the definitions of which have been detailed below:

$$
\begin{array}{ll}
K_{r}=\frac{K}{K_{I C}} & \text { Equation 10 } \\
L_{r}=\frac{\sigma_{r e f}}{\sigma_{Y}} & \text { Equation 11 }
\end{array}
$$

where $K$ is the stress intensity factor, $K_{I C}$ is the fracture toughness (which can be estimated using $J=K^{2}\left(1-v^{2}\right) / E$ correlation where $v$ is the Poisson's ratio), $\sigma_{Y}$ is the yield stress of the material and $\sigma_{r e f}$ is the reference stress parameter, the solutions of which are available in R6 handbook for a wide range of geometries [52]. If the assessed $\left(K_{r}, L_{r}\right)$ point falls inside the safety locus the cracked component is considered to be safe to operate, however if it falls outside the locus it implies that the cracked component is operating in an unsafe mode.

Failure assessment diagrams have been plotted assuming the upper bound and lower bound mechanical and fracture properties summarised in Table 7 and Table 9 for each material microstructure (BM, HAZ and WM), and the corresponding critical crack size has been calculated for each case. It has been assumed in the analyses that the locked-in tensile residual stress in the monopile weldment is as large as the yield stress of the material (which is a conservative assumption) and the fatigue crack aspect ratio (ratio of the minor axis to major axis in R6 analysis) is 0.6 . The minimum and maximum critical crack size estimates obtained from the R6 analysis are summarised in Table 10 and an exam of a FAD analysis is shown in Figure 14. As seen in Table 10, depending on whether the monopile fails in the BM, HAZ or WM the critical crack size varies significantly depending on the material microstructure and level of scatter in mechanical and fracture properties of the material. This table shows that the shortest critical crack size is observed when failure takes place in the WM. Also seen in this table is that a conservative assessment can be made by employing the minimum mechanical and fracture properties in the analysis. This implies the importance of crack path detection in monopiles using suitable non-destructive testing (NDT) techniques and the need to employ appropriate values of mechanical and fracture properties to assess the structural integrity of the offshore wind monopiles with acceptable safety margin from failure. 
Table 10 - Critical crack size estimated using the R6 procedure

\begin{tabular}{ccc}
\hline & \multicolumn{2}{c}{ Critical Crack size (mm) } \\
\hline & Minimum & Maximum \\
\hline BM & 37.0 & 45.3 \\
\hline HAZ & 44.3 & 51.2 \\
\hline WM & 35.9 & 40.8 \\
\hline
\end{tabular}

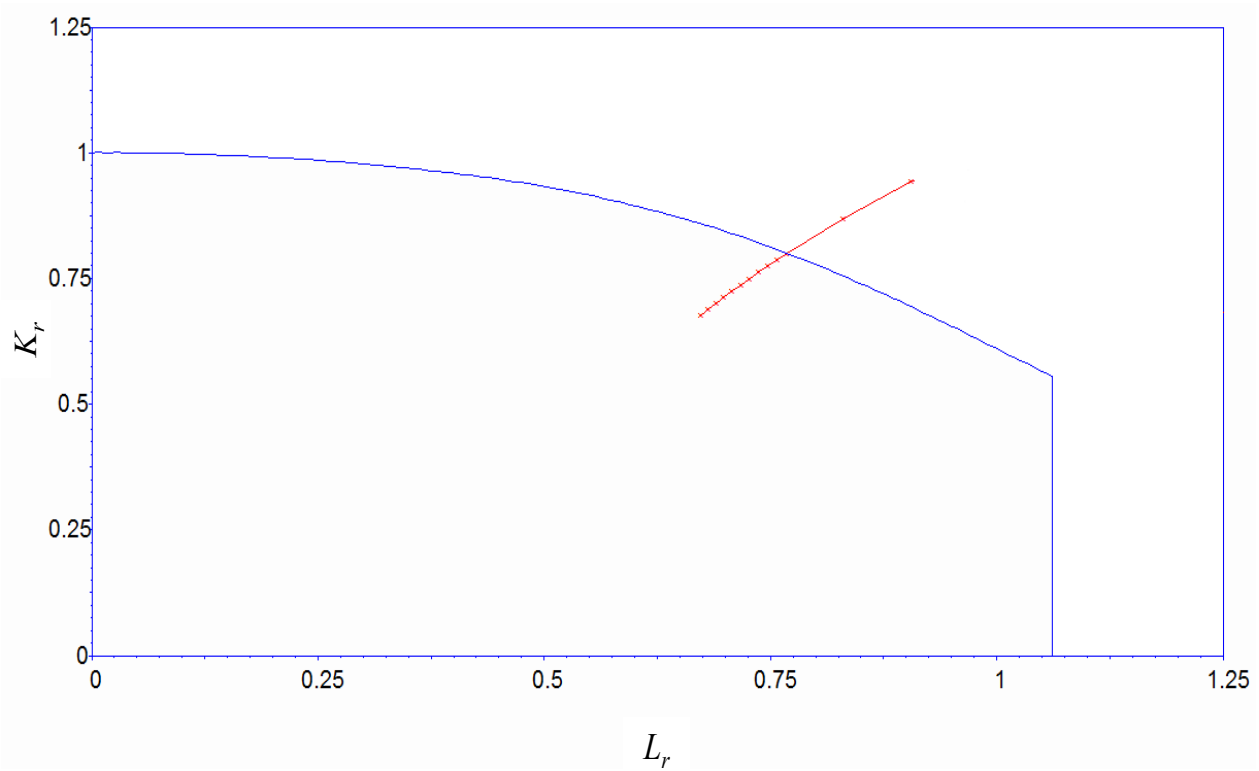

Figure 14 - An example of Level III failure assessment diagram for WM (by considering minimum mechanical and fracture properties)

\subsection{Challenges and Recommendations}

This research programme was focused on the level of scatter observed in the mechanical and fracture properties of monopile weldments, rather than the thickness effects on these properties. Although tensile, Charpy and fracture toughness specimens were extracted from two different plate thicknesses $(50 \mathrm{~mm}$ and $90 \mathrm{~mm})$, the test specimens had the same design and dimensions and therefore the differences in the observed results cannot be associated with the thickness effects. However, the experimental data in the literature on other types of steels have shown that a decreasing trend can be observed in the yield stress, UTS and fracture toughness of the material as the component thickness increases [23]. This implies that for the monopiles fabricated from very high thickness welded plates (e.g. $150 \mathrm{~mm}$ ) it is essential to consider the reduction in the mechanical and fracture properties in structural life assessments while ensuring that the new designs are economically efficient and not overly conservative.

It is also known that the test temperature influences the mechanical and fracture properties of the material $[9,12,53,54]$. In addition, the welding residual stresses play an important role in the crack initiation and propagation behaviour in monopiles and therefore need to 
be considered in structural integrity assessments. Considering the key challenges given above, it is recommended that more tests on different specimen sizes at various temperature (within the operational ranges in the offshore wind farms) are performed in the future work on the welded plates with a wider range of strength mismatch ratio. This will help to quantify the thickness (i.e. size), temperature and welding residual stress effects on the mechanical response of monopile welded structures and investigating their subsequent impact on the life assessment of offshore wind turbine monopiles. It is also recommended to consider a wider range of steels for fabrication of monopiles and compare their life expectancy in the harsh offshore environment with those materials which are currently in use. The recommended future study can assist the offshore wind industry to make informed decisions in the design and operation of the next generation of offshore wind turbine foundations by optimising the monopoile geometry (i.e. diameter and thickness) and potentially reducing the capital expenditure costs by minimising the volume of material used in fabrication of future monopiles.

\section{Conclusions}

Material characterisation tests have been conducted on the BM, HAZ and WM specimens extracted from S355 welded plates typical of offshore wind turbine monopile foundations. The results have shown that an approximate scatter of up to $\pm 25 \%$ can be observed in the Charpy impact energy results and the yield stress of the material, even in the plates produced by the same manufacturer. The results have also revealed that the lowest average Charpy impact energy and $J_{\max }$ values were observed in the WM, which has exhibited the highest average yield stress, compared to BM and HAZ. Moreover, a consistent trend, with an increase in the yield stress and hardness results from BM to WM, were observed confirming that yield strength and hardness measurements for S355 weldments are proportional to each other. The fracture toughness test results have shown that the highest $J_{I C}$ value is found in the HAZ, followed by the BM and then the WM. The impact of the obtained mechanical and fracture properties on engineering critical assessment of monopiles has been examined using the R6 life assessment procedure. The results have shown that for the slightly overmatched welded plates examined in this study the shortest critical crack size is observed when failure takes place in the WM and the calculations are very sensitive to the experimental scatter band. More tests are recommended to be conducted in the future work in order to investigate the specimen size, temperature and residual stress effects on the structural design and integrity of monopiles.

\section{Acknowledgments}

The authors would like to acknowledge the help and contribution of the SLIC steering committee, project technical support team, fabricators, specimen manufacturers, AMEC, FORCE and OCAS Test Centres, and finally members of the technical delivery team at 
Cranfield University. This work was supported by EPSRC under Grant EP/L016303/1 (Renewable Energy Marine Structures (REMS) Centre for Doctoral Training).

\section{References}

[1] Adedipe O, Brennan F, Kolios A. Review of corrosion fatigue in offshore structures: Present status and challenges in the offshore wind sector. Renewable and Sustainable Energy Reviews. 2016;61:141-54.

[2] Institution BS. Hot rolled products of non-alloy structural steels. 1993.

[3] Outinen J, Mäkeläinen P. Transient state tensile test results of structural steel S355

(RAEX 37-52) at elevated temperatures. Rakenteiden mekaniikka. 1995;28:3-18.

[4] Kocańda D, Hutsaylyuk V, Ślęzak T, Torzewski J, Nykyforchyn H, Kyryliv V. Fatigue crack growth rates of S235 and S355 steels after friction stir processing. Materials Science Forum: Trans Tech Publ; 2012. p. 203-10.

[5] Lewandowski J, Rozumek D. Cracks growth in S355 steel under cyclic bending with fillet welded joint. Theoretical and Applied Fracture Mechanics. 2016;86:342-50.

[6] Qian X, Ou Z, Swaddiwudhipong S, Marshall PW. Brittle failure caused by lamellar splitting in a large-scale tubular joint with fatigue cracks. Marine Structures.

2013;34:185-204.

[7] Häßler D, Hothan S. Mechanische Hochtemperatureigenschaften von

Stahlzuggliedern aus kaltverformtem Blankstahl der Festigkeitsklasse S355. Stahlbau. 2015;84:332-40.

[8] Sokolov M, Salminen A, Kuznetsov M, Tsibulskiy I. Laser welding and weld hardness analysis of thick section S355 structural steel. Materials \& Design.

2011;32:5127-31.

[9] Wang Y, Zhou H, Shi Y, Chen H. Study on fracture toughness indices of Chinese structural steel and weld metal. The Twentieth International Offshore and Polar Engineering Conference: International Society of Offshore and Polar Engineers; 2010. [10] Martancik B, Martancikova G, Ulrich K, Barta J. In defects diagnostics by using NDT methods and their impact on remaining life. Annals of DAAAM \& Proceedings. 2011:1287-9.

[11] Kálna K, Vitásek M. The New Danube Bridge in Bratislava-Requirements on Materials and Fabrication of Bridge Structure. Welding in the World. 2005;49:90-9. [12] Brnic J, Canadija M, Turkalj G, Lanc D. Behaviour of S 355JO steel subjected to uniaxial stress at lowered and elevated temperatures and creep. Bulletin of materials science. 2010;33:475-81.

[13] Patel J, Jansto S. Niobium high strength steels for greener wind power generation. Millenium Steel 2012:171-5.

[14] Prokolab M, Milutinovic Z, Markovic N, Jovanovic D, Prvulovic M, Ignjatovic J, et al. Diagnosing stress state of the welded structure $p$ frame rotary excavator obtained by thermography and tensometry and fracture mechanical method. Innovative technologies for joining advanced materials2011.

[15] Vukojevic N, Oruc M, Vukojevic D, Hadzikadunic F, Beganovic O. Performance analysis of substitution of applied materials using fracture mechanics parameters.

Tehnicki Vjesnik. 2010;17:411-8.

[16] Kern A, Niessen T, Schriever U, Tschersich H-J. Production and Properties of High-Strength Steel Plates for Offshore Applications. The Fourteenth International Offshore and Polar Engineering Conference: International Society of Offshore and Polar Engineers; 2004. 
[17] Moitra A, Parameswaran P, Sreenivasan P, Mannan S. A toughness study of the weld heat-affected zone of a 9Cr-1Mo steel. Materials characterization. 2002;48:55-61. [18] Adedipe O, Brennan F, Mehmanparast A, Kolios A, Tavares I. Corrosion fatigue crack growth mechanisms in offshore monopile steel weldments. Fatigue \& Fracture of Engineering Materials \& Structures. 2017;40:1868-81.

[19] Mehmanparast A, Brennan F, Tavares I. Fatigue crack growth rates for offshore wind monopile weldments in air and seawater: SLIC inter-laboratory test results.

Materials \& Design. 2017;114:494-504.

[20] Adedipe O, Brennan F, Kolios A. Corrosion fatigue crack growth in offshore wind monopile steel HAZ material. Analysis and Design of Marine Structures V, 5th International Conference on Marine Structures, Taylor and Francis Group2015. p. 20712.

[21] Adedipe O, Brennan F, Kolios A. A relative crack opening time correlation for corrosion fatigue crack growth in offshore structures. Fatigue \& Fracture of Engineering Materials \& Structures. 2016;39:395-411.

[22] Neves J, Loureiro A. Fracture toughness of welds - effect of brittle zones and strength mismatch. Journal of materials processing technology. 2004;153:537-43. [23] Green G, Knott J. On effects of thickness on ductile crack growth in mild steel. Journal of the Mechanics and Physics of Solids. 1975;23:167-83.

[24] Cray M, Luxmoore A, Sumpter J. The effect of weld metal strength mismatch on J and CTOD. EGF91991.

[25] Kirk MT, Dodds Jr RH. The effect of weld metal strength mismatch on the deformation and fracture behavior of steel butt weldments. University of Illinois Engineering Experiment Station. College of Engineering. University of Illinois at Urbana-Champaign.; 1991.

[26] Wallin K. The size effect in KIc results. Engineering Fracture Mechanics. 1985;22:149-63.

[27] ASTM. E 1820-09: Standard Test Method for Measurement of Fracture Toughness. Annual Book of ASTM Standards. 2009;03.01:1024-57.

[28] Anderson TL. Fracture Mechanics: Fundamentals and Application. Boston: CRC Press; 1991.

[29] British Standard B. 7448: Fracture mechanics toughness tests. British Standards Institute, London. 1997.

[30] ISO P. 148-1 Metallic materials-Charpy pendulum impact test. Test method:

British Standards Institution. 2009.

[31] Hever M, Schröter F. Modern steel-High performance material for high performance bridges. 5th International Symposium on Steel Bridges2003. p. 80-91. [32] Standard A. E23-09: Standard Test Method for Notched Bar Impact Testing of Metallic Materials. Annual Book of ASTM Standards, ASTM, West Conshohocken, PA. 2009.

[33] BS. IBS EN 10355:2013 Chemical analysis of ferrous materials. Inductively coupled plasma optical emission spectrometric analysis of unalloyed and low alloyed steels. Determination of $\mathrm{Si}, \mathrm{Mn}, \mathrm{P}, \mathrm{Cu}, \mathrm{Ni}, \mathrm{Cr}$, Mo and $\mathrm{Sn}$, following dissolution with nitric and sulphuric acids [Routine method]. London: British Standards Institution; 2013.

[34] ASTM. E1251-11: Standard Test Method for Analysis of Aluminum and Aluminum Alloys by Spark Atomic Emission Spectrometry. 
[35] ISO E. 6507-1. Metallic Materials_-Vickers Hardness Test. International Organization for Standardization: Geneva, Switzerland. 2005:1996-44.

[36] ISO BSE. 17639, Destructive tests on welds in metallic materials. Macroscopic and microscopic examination of welds BSI. 2013.

[37] ISO E. 6892-1. Metallic materials-Tensile testing-Part 1: Method of test at room temperature. International Organization for Standardization. 2009.

[38] Acar MO, Gungor S. Experimental and numerical study of strength mismatch in cross-weld tensile testing. The Journal of Strain Analysis for Engineering Design.

2015;50:349-65.

[39] Lim S, Kim S, Lee C-G, Kim SJ, Yim CD. Tensile behavior of friction-stir-welded AZ31-H24 Mg alloy. Metallurgical and Materials Transactions A. 2005;36:1609-12. [40] ESIS. P2-92: Procedure for Determining the Fracture Behaviour of Materials. European Structural Integrity Society Publication; 1992.

[41] Paredes M, Ruggieri C. Further results in J and CTOD estimation procedures for SE(T) fracture specimens - Part II: Weld centerline cracks. Engineering Fracture Mechanics. 2012;89:24-39.

[42] Paredes M. Plastic limit load and its application to the fracture toughness testing for heterogeneous single edge notch tension specimens. Fatigue \& Fracture of Engineering Materials \& Structures. 2014;37:265-79.

[43] Xuan F-Z, Tu S-T, Wang Z. A modification of ASTM E 1457 C* estimation equation for compact tension specimen with a mismatched cross-weld. Engineering Fracture Mechanics. 2005;72:2602-14.

[44] Richard HA, Sander M. Fatigue Crack Growth: Springer; 2016.

[45] Tregoning R. Strength and Crack Resistance Behavior of Mismatched Welded Joints. NAVAL SURFACE WARFARE CENTER CARDEROCK DIV ANNAPOLIS MD METALS DEPT; 1995.

[46] Mathias LLS, Sarzosa DFB, Ruggieri C. Effects of specimen geometry and loading mode on crack growth resistance curves of a high-strength pipeline girth weld.

International Journal of Pressure Vessels and Piping. 2013;111-112:106-19.

[47] Zhang P, Li S, Zhang Z. General relationship between strength and hardness. Materials Science and Engineering: A. 2011;529:62-73.

[48] Harrison PL. Structural Integrity assessment procedures for European industry. SINTAP, Sub-Task 13: Weld Strength Mismatch Effects - Multipass Weld Evaluation. 1999.

[49] Dong P, Zhang J. Residual stresses in strength-mismatched welds and implications on fracture behavior. Engineering Fracture Mechanics. 1999;64:485-505.

[50] Lin G, Meng X-G, Cornec A, Schwalbe K-H. The effect of strength mis-match on mechanical performance of weld joints. International journal of fracture. 1999;96:37-54. [51] Cam G, Erim S, Yeni C, Kocak M. Determination of mechanical and fracture properties of laser beam welded steel joints. WELDING JOURNAL-NEW YORK-. 1999;78:193-s.

[52] R6. Assessment of the Integrity of Structures Containing Defects. British Energy Generation Ltd. UK; 2006.

[53] Mills WJ. Fracture toughness of type 304 and 316 stainless steels and their welds. International Materials Reviews. 1997;42:45-82.

[54] Zhu X-K, Joyce JA. Review of fracture toughness (G, K, J, CTOD, CTOA) testing and standardization. Engineering Fracture Mechanics. 2012;85:1-46. 